\title{
THE POTENTIAL OF TANTALUM-DOPED MESOPOROUS BIOACTIVE GLASSES FOR HEMOSTASIS.
}

\author{
by \\ Andrew Mendonca \\ BASc in Nanotechnology Engineering, University of Waterloo, Canada, 2015 \\ A thesis presented to Ryerson University \\ in partial fulfillment of the requirements for degree of \\ Master of Applied Science \\ in the program of \\ Biomedical Engineering
}

Toronto, Ontario, Canada, 2019

(C) Andrew Mendonca 2019 


\section{Author's declaration}

I hereby declare that I am the sole author of this thesis. This is a true copy of the thesis, including any required final revisions, as accepted by my examiners.

I authorize Ryerson University to lend this thesis to other institutions or individuals for the purpose of scholarly research.

I further authorize Ryerson University to reproduce this thesis by photocopying or by other means, in total or in part, at the request of other institutions or individuals for the purpose of scholarly research.

I understand that my thesis may be made electronically available to the public. 


\title{
Abstract \\ INVESTIGATION OF THE POTENTIAL OF TANTALUM MESOPOROUS BIOACTIVE GLASSES FOR HEMOSTASIS
}

\author{
Andrew Mendonca \\ Master of Applied Science, 2019 \\ Biomedical Engineering \\ Ryerson University
}

Synthesis and characterization of the first mesoporous bioactive glasses (MBGs) containing tantalum (Ta) are reported, alongside their potential as hemostats. A series of silica MBGs with the molar composition of $(80-\mathrm{x}) \% \mathrm{Si}, 15 \% \mathrm{Ca}, 5 \% \mathrm{P}$ and $\mathrm{x} \% \mathrm{Ta}$, with $\mathrm{x}=0$ to 10 , were synthesized by the sol-gel method. Increasing Ta content from 1 to $10 \mathrm{~mol} \%$ caused a decrease in the surface area and pore volume of $\sim 20 \%$ and $\sim 35 \%$, respectively, due to the increase in non-bridging oxygens and mismatch of thermal expansion coefficient which creates discontinuities in the ordered channel structure. However, the effect is not significant on the amount of ions released from the samples into deionized water, for short durations ( $<60 \mathrm{~min}$ ). In a mouse tail cut model, a significant decrease $(\geq 50 \%)$ in average bleeding time was found for Ta-MBGs compared to controls (commercial hemostat Arista® and a Ta-free MBG). There was no significance in hemolytic activity between plain blood and when MBG is present and cytotoxicity results show that increasing Ta content from 0 to $10 \%$ reduced MBG toxicity by more than $15 \%$; this effect was visually confirmed by live/dead cell assays. Further studies are proposed to determine the mechanism of $\mathrm{Ta}$ involvement with the hemostatic process. 


\section{Acknowledgements}

I would like to thank Dr. Mark Towler for his guidance and continuous support during my degree. His enthusiasm, motivation and approachable attitude helped me to survive many problems. I am glad that he took me under his supervision.

I am very grateful to my colleague Saidur Rahman for assisting me with experimental work, helping me with data analysis and keeping me fed.

I appreciate the financial support from Canadian Institute of Health Research (CIHR) Project [appl. \# 366716. A novel approach to treating hemorrhage with mesoporous bioactive glasses] for funding my masters, and the Biomedical Engineering department for a scholarship.

I am grateful to Dr. Adel Alhalawani and Dr. Omar Rodriguez for their help finding equipment, discussions about the data, direction in writing this thesis and proofreading of my work. I would also like to thank Audrey Darabie (CSB, University of Toronto, Canada) for assistance in TEM, Loraine Chu (Waldman Lab, St. Michael's Hospital, Canada) for conducting the cell work and helping analyze data, and Dr. Owen Clarkin (Mechanical and Manufacturing Engineering, Dublin City University, Ireland) for conducting the nitrogen adsorption experiments and helping to disseminate the data.

Finally, I must express my gratitude to my family and friends for their emotional support and encouragement during my degree. 
Dedication

To little JJ. 


\section{Table of contents}

Author's declaration $\quad$ ii

Abstract iii

Acknowledgements iv

Dedication $\quad \mathrm{V}$

List of tables $\quad$ ix

List of figures $\quad x$

Nomenclature $\quad$ xii

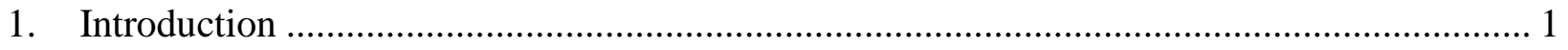

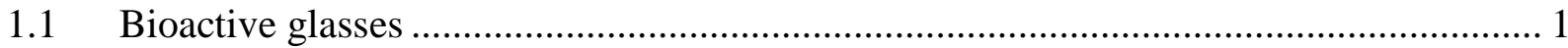

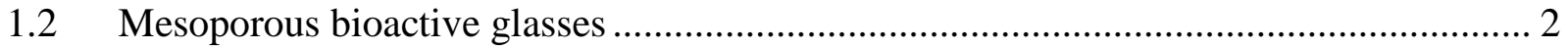

1.2.1 Sol-gel method for MBGs...................................................................... 2

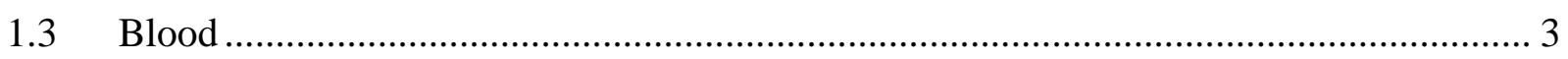

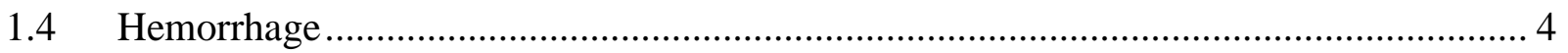

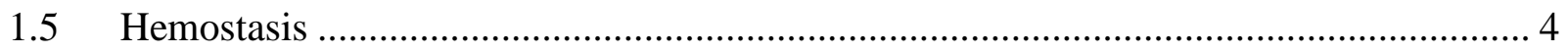

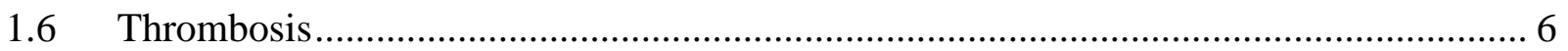

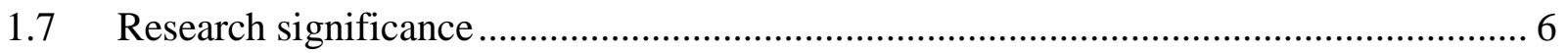

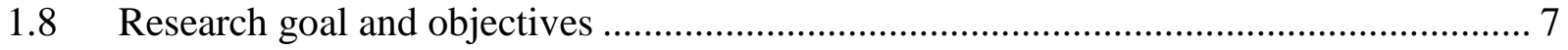

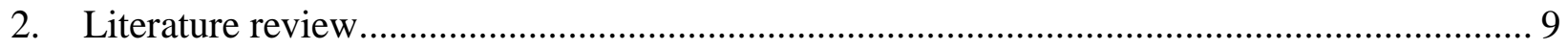

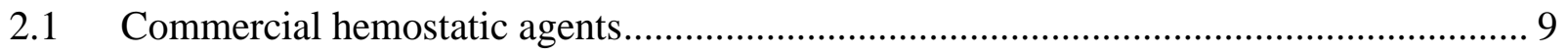

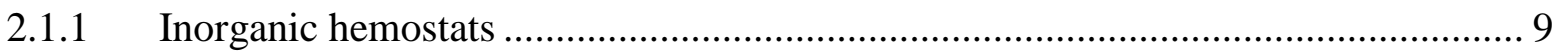

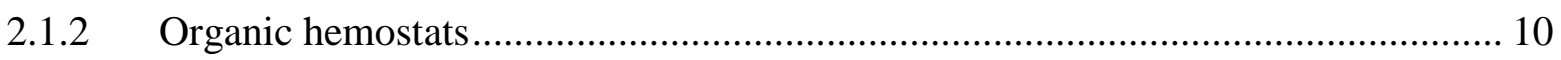

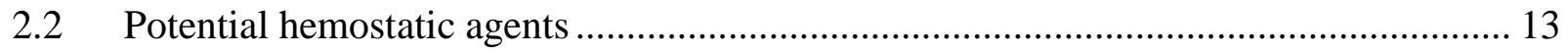

2.2.1 Hydrogel based hemostats .................................................................... 13

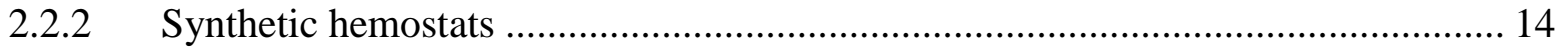

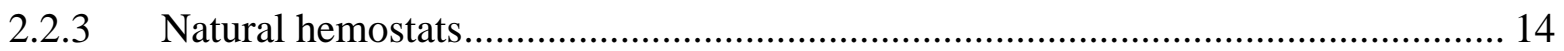

2.3 Bioactive glasses for hemostasis ...................................................................... 16

2.3.1 Mesoporous bioactive glasses for hemostasis........................................... 17 


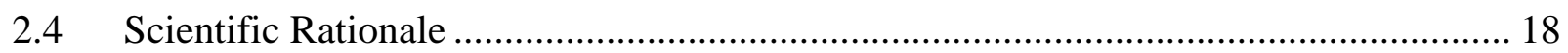

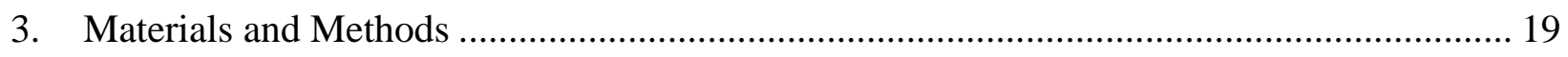

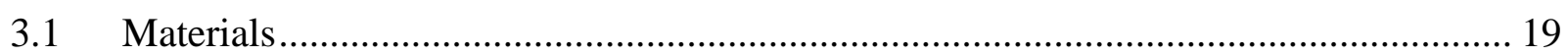

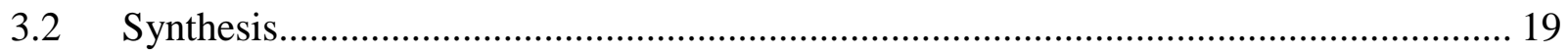

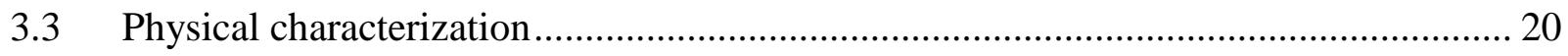

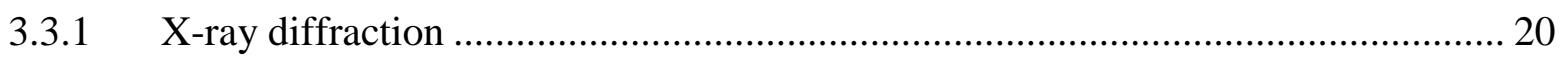

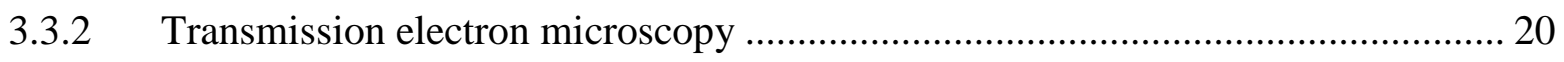

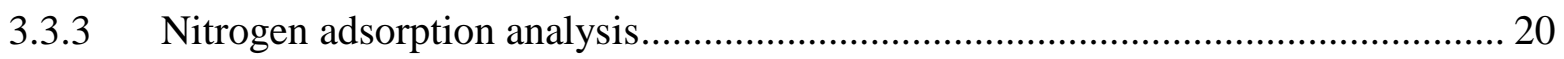

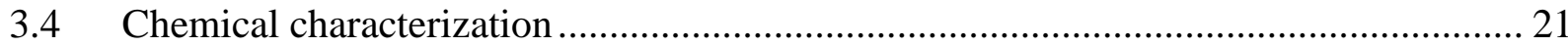

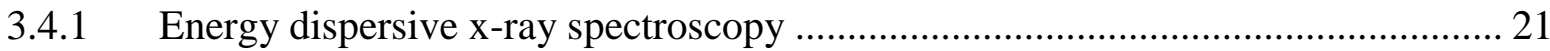

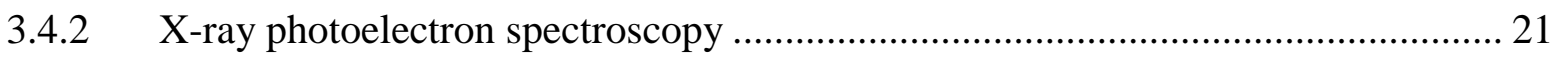

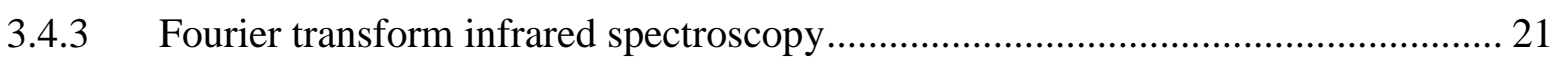

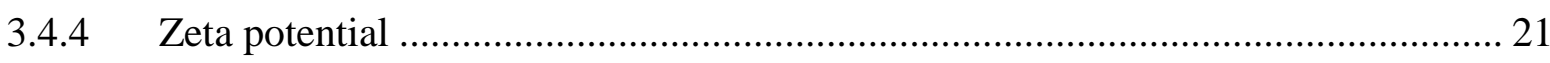

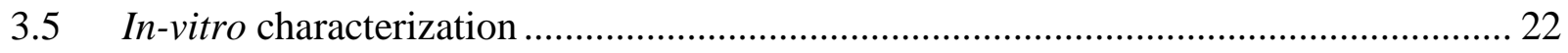

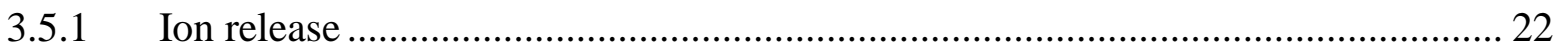

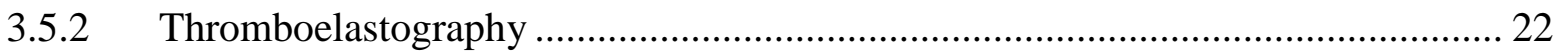

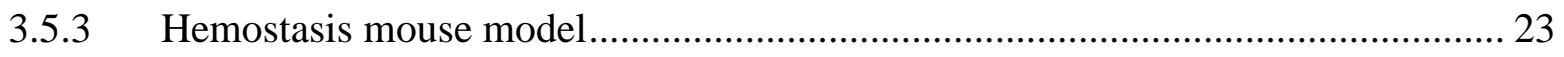

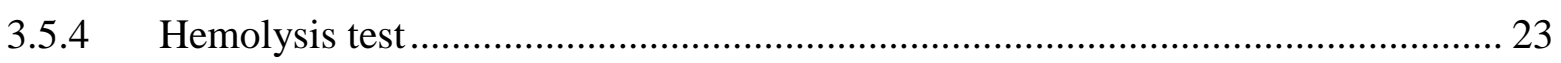

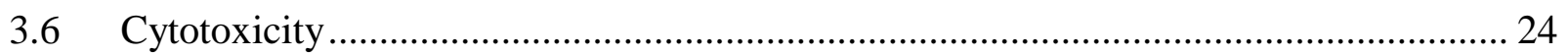

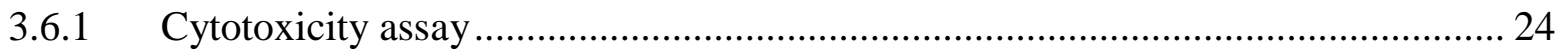

3.6.2 Live/deal cell viability assay …………………................................................... 25

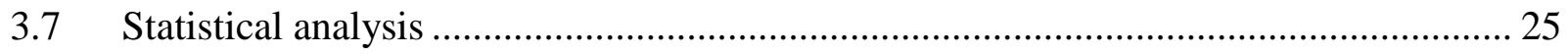

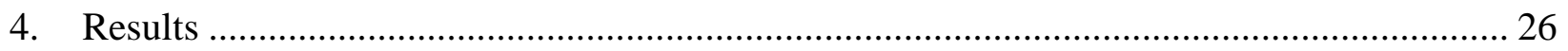

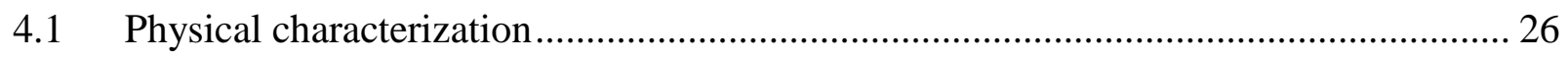

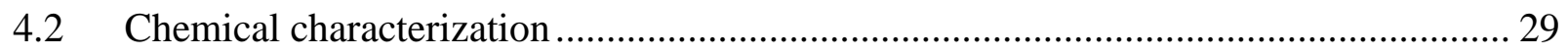

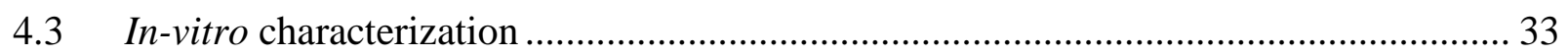

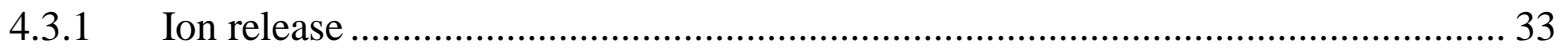

4.3.2 Thromboelastography ……………………............................................... 33

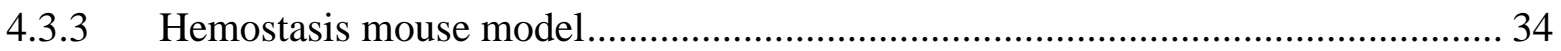




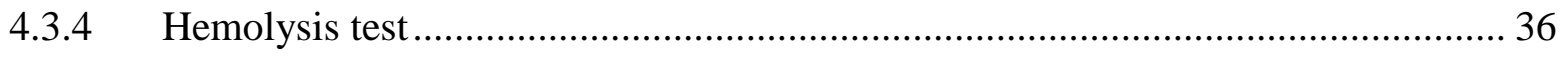

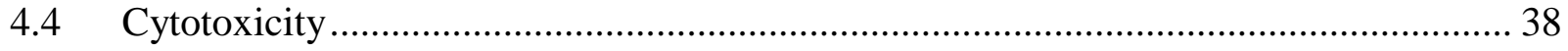

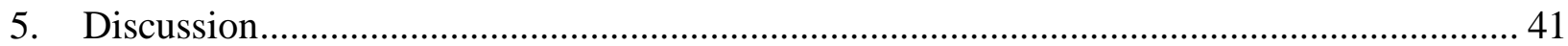

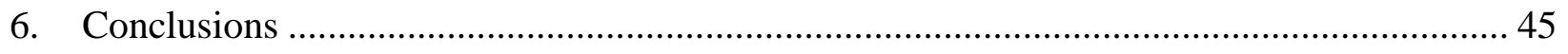

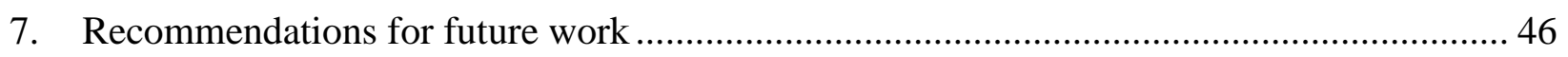

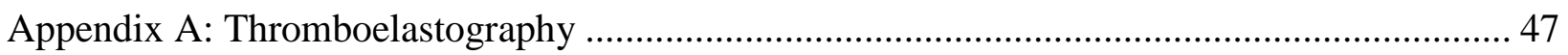

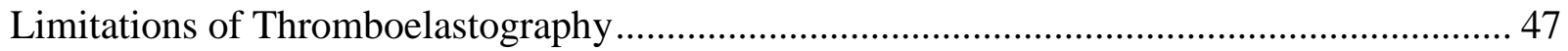

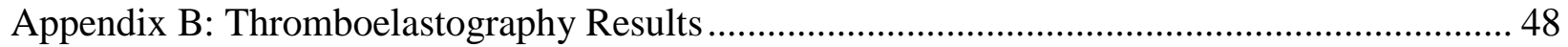

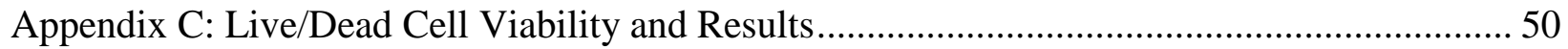

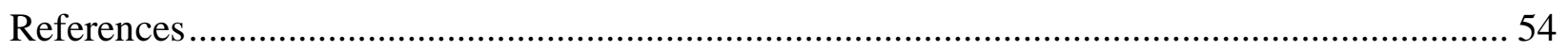




\section{List of Tables}

Table 2.1: Summary of commercial hemostatic agents .................................................... 12

Table 2.2: Summary of potential hemostatic agents being researched ..................................... 16

Table 3.1: Compositions of synthesized mesoporous bioglasses (mol\%). ............................... 19

Table 4.1: BET surface area and, BJH pore volume and pore diameter of all samples. ............. 27

Table 4.2: Theoretical wt. \% of MBG compositions ............................................................ 29

Table 4.3: Composition of MBG samples from EDS (wt. \%) ................................................ 29

Table 4.4: Normalized XPS data of MBG compositions (wt. \%) .......................................... 30

Table 4.5: BO and NBO binding energy, atomic percentage and shifting energy for MBG

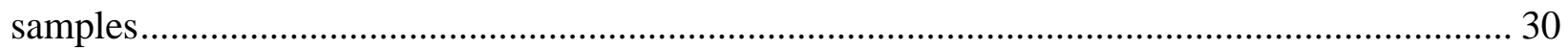

Table 4.6: Zeta potential of MBGs in water and polystyrene latex bead solution..................... 32

Table 4.7: R time performance of different powder samples with respect to no powder added .. 33

Table 4.8: Significance ( $\mathrm{p}$-values) between mean tail bleeding times from the hemostasis model. 


\section{List of Figures}

Figure 1.1: Representation of EISA method [3] ........................................................ 3

Figure 1.2: The blood coagulation cascade, including the intrinsic, extrinsic and common

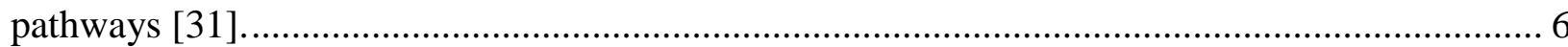

Figure 4.1: XRD results for MBG showing amorphous nature of all glasses. ........................ 26

Figure 4.2: Small angle XRD results of MTa samples showing the two characteristic peaks of

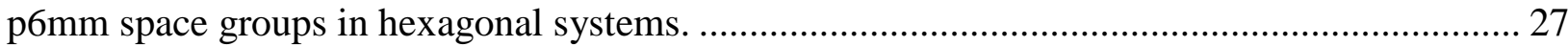

Figure 4.3: TEM images of a) MTa-0, b) MTa-0.5, c) MTa-1, d) MTa-5 and e) MTa-10 glasses. Arrow sign indicates discontinuity in the channel. The 2D hexagonal framework incurs more discontinuities as the Ta content increases. .................................................................... 28 Figure 4.4: High resolution O1s spectrum for a) MTa-0, b) MTa-0.5, c) MTa-1, d) MTa-5 and e) MTa-10. The graphs show the BO peak, NBO peak and the combined peak. As Ta content is

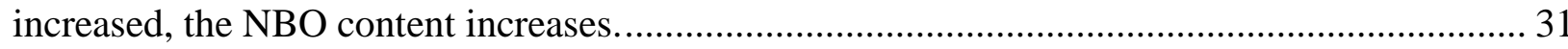

Figure 4.5: FTIR spectra of MTa samples with associated silicon bonds. 32 Figure 4.6: Ion release profiles from MBGs for silicon, calcium, phosphorous and tantalum. Error bars are standard deviations. 34

Figure 4.7: Tantalum containing bioactive glasses decreased the tail bleeding time in c57bl/6 mice. Results from hemostasis model are represented with individual symbols $(\bullet)$ representing one mouse; error bars represent standard error of the mean $(n=5-10)$.

Figure 4.8: Fitting curve of the hemolysis test. Only three points fall into the linear range of the curve; the fourth point is omitted from the equation and the fifth point is out of measurement range.

Figure 4.9: \% Lysis of each MTa sample and the negative control. Absorbance values were fitted to the equation in Figure 4.8, multiplied by the dilution factor (20) and graphed. Error bars represent standard deviations; * represents only $\mathrm{n}=3$ samples used.

Figure 4.10: Comparison of MTa-1 (left) and MTa-0 (right) samples. Some RBCs got into the MTa-1 samples because the blood clotted, and the plasma gelled with the cells.

Figure 4.11: Cytotoxicity data of the MTa glasses normalized to control group without any sample. Glass composition and dose response was analyzed for each MTa sample. Increasing absorbance indicates more living cells. 
Figure 4.12: Live (green) and dead (red) assay images of a) MTa-0, b) MTa-0.5, c) MTa-1, d) MTa-5 and e) MTa-10, all at $1 \mathrm{mg}$ dose. Increasing Ta content shows increasing live cells....... 40 


\section{Nomenclature}

\begin{tabular}{|c|c|}
\hline $\mathrm{ABS}$ & Ankaferd Blood Stopper \\
\hline $\mathrm{ACS}$ & Advanced clotting sponge \\
\hline ADP & adenosine diphosphate \\
\hline APTT & activated partial thromboplastin \\
\hline BET & $\begin{array}{l}\text { Brunauer, Emmett and Teller schema; references surface area } \\
\text { measurement }\end{array}$ \\
\hline BG & bioactive glass \\
\hline $\mathrm{BJH}$ & Barrett, Joyner, Halenda schema; references pore volume and size \\
\hline $\mathrm{BO}$ & Bridging oxygen \\
\hline CTE & Coefficient of thermal expansion \\
\hline DI & deionized \\
\hline DMEM & Dulbecco's modified Eagle medium \\
\hline EDS & Energy dispersive $\mathrm{x}$-rays spectroscopy \\
\hline EDTA & Ethylenediaminetetraacetic acid (anticoagulant) \\
\hline EISA & evaporation induced self assembly \\
\hline FBS & Fetal bovine serum \\
\hline FDA & Food and Drug Administration \\
\hline FTIR & Fourier transform infrarerd spectropscopy \\
\hline HA & hydroxy apatite \\
\hline $\mathrm{HCA}$ & hydroxycarbonate apatite \\
\hline $\mathrm{HNC}$ & hydrogel nanocomposite \\
\hline MA & Maximum amplitude in TEG \\
\hline MBG & Mesoporous bioactive glass \\
\hline $\mathrm{mRDH}$ & modified rapid deployment hemostat \\
\hline MTT & 3-(4,5-dimethylthiazol-2-yl)-2,5-diphenyltetrazolium bromide \\
\hline $\mathrm{NBO}$ & non-bridging oxygen \\
\hline $\mathrm{NBO}$ & Non-bridging oxygen \\
\hline $\mathrm{NIH}$ & National Institute of Health \\
\hline PBS & Phosphate buffered saline \\
\hline
\end{tabular}




\begin{tabular}{|l|l} 
PV & pore volume \\
QCG & QuikClot \\
R & QuikClot Combat Gauze \\
RBC & Time taken for clot initiation in TEG \\
SA & red blood cell \\
SAXRD & Small angle x-ray diffraction \\
SEM & Scanning electron microscope \\
TEG & Thromboelastography \\
TEM & Transmission electron microscopy \\
TEOS & tetraethylorthosilicate \\
TEP & triethylphosphate \\
TXA2 & thromboxan A2 \\
USA & United States of America (also called US) \\
vWF & Von Willebrand factor \\
WAXRD & Wide angle x-ray diffraction \\
WBC & white blood cell \\
WS & WoundStat \\
XPS & Rignificance value chosen for statistical analyses \\
$\alpha$ & Rate of clot growth in TEG \\
&
\end{tabular}




\section{Introduction}

\subsection{Bioactive glasses}

Glasses are inorganic, non-crystalline solids that are usually optically transparent, hard and brittle [1]. They are usually made by water quenching of molten precursor oxides, known as the melt quench method [1]. Bioactive glasses (BGs) are glasses that can elicit a specific biological response and bond to host tissue [2]. The first bioactive glass was synthesized by Hench et al. and was called Bioglass $®$ [3]. It consisted of $46.1 \mathrm{~mol} \% \mathrm{SiO}_{2}, 24.4 \mathrm{~mol} \% \mathrm{Na}_{2} \mathrm{O}, 26.9 \mathrm{~mol} \% \mathrm{CaO}$ and $2.6 \mathrm{~mol} \% \mathrm{P}_{2} \mathrm{O}_{5}$, and was made using the melt quench method. Bioglass ${ }^{\circledR}$ was originally designed to chemically bond with bone tissue and promote bone repair after injury [4]. The mechanism for this bone bonding is attributed to the hydroxycarbonate apatite (HCA) layer that forms on the glass surface when dissolving in bodily fluid. HCA formation occurs in five stages: cation exchange, silanol creation, silanol polymerization, $\mathrm{Ca}^{2+} / \mathrm{PO}_{4}{ }^{3-}$ incorporation, and HCA crystallization [3]. Cation exchange between the glass $\left(\mathrm{Ca}^{2+}\right.$ and $\left.\mathrm{Na}^{+}\right)$and the medium (usually $\mathrm{H}^{+}$) changes the $\mathrm{pH}$ of the solution, making it more basic. This causes dissolution of the silica backbone and creation of silanol ( $\mathrm{Si}-\mathrm{OH})$ groups on the glass surface [3]. In high silica content glasses $\left(>60 \mathrm{~mol} \% \mathrm{SiO}_{2}\right)$, the cation exchange halts because of the high network connectivity in the bulk of the glass (each Si bonded to $4 \mathrm{O}$ atoms). However, with the low silica content of Bioglass ${ }^{\circledR}$, the glass network is weaker (each $\mathrm{Si}$ bonded to $\sim 2 \mathrm{O}$ atoms) and so cation exchange and silanol creation continues further into the bulk glass [3]. The silanol groups on the surface then undergo condensation polymerization. $\mathrm{Ca}^{2+} / \mathrm{PO}_{4}{ }^{3-}$ from the glass and excess $\mathrm{Ca}^{2+}$ and $\mathrm{PO}_{4}{ }^{3-}$ from the medium move to the silanol surface and create an amorphous calcium-phosphate layer [3]. Lastly, hydroxyls and carbonates from the medium are incorporated into the calcium phosphate layer and crystalize into HCA. The HCA layer created by Bioglass ${ }^{\circledR}$ is similar in composition to bone and so chemical bonding can occur between it and the mineral phase of bone [3]. The surface is also suitable for cell attachment, so colonization and proliferation of osteoblasts (bone creating cells) occur, creating a mechanically more stable bond [5].

The mechanism for tissue bonding to bioactive glasses relies on the initial dissolution of the glass, and release of its ions to initiate further reactions [2]. Therefore, the dissolution of the silica backbone is an important parameter that will determine the rate of glass reactivity. Lower silica content (below $60 \mathrm{wt} . \%$ ) results in faster dissolution and faster reactions [6]. Modifying additives 
(e.g. $\mathrm{Na}, \mathrm{Ca}, \mathrm{P}$, etc.) affect the melting temperature of the glass and the reactions it undergoes. They further disrupt the glass network, introducing non-bridging silicon oxygen bonds (Si-NBOs). The number of these Si-NBOs is proportional to bioactivity with increasing numbers increasing bioactivity [3]. The addition of other multivalent ion such as $\mathrm{Ti}^{3+}$ or $\mathrm{Al}^{3+}$ can lower dissolution rate [7], [8] and adding therapeutic ions such as $\mathrm{Cu}^{2+}$ and $\mathrm{Sr}^{2+}$ can provide effects such as angiogenesis, antibacterial effects, and osteo-stimulation [9], [10]. However, a high content of certain ions can also lead to cytotoxicity [11] and so more silica content is favoured in these situations. Bioactive glasses cannot be synthesized with $>65 \mathrm{~mol} \%$ silica, using the conventional melt-quench method, due to both the high silica content reducing dissolution and the increased potential of phase separation of the reactants [3], [12]. Therefore, new methods are being evaluated to synthesize bioactive glasses.

\subsection{Mesoporous bioactive glasses}

Mesoporous bioactive glasses (MBGs) are those that have nanometer sized pores in their structure. Along with other mesoporous materials, they have gained wide spread attention in the last two decades because of their high specific surface area (SA) and pore volume (PV). Conventional bioactive glasses have SA of the order of $0-5 \mathrm{~m}^{2} / \mathrm{g}$ and PV in the range of $0-40 \mu \mathrm{L} / \mathrm{g}$ [13]. However,

MBGs have SA and PV of $>100 \mathrm{~m}^{2} / \mathrm{g}$ and $>200 \mu \mathrm{L} / \mathrm{g}$, respectively, with some researchers reporting SAs up to $1200 \mathrm{~m}^{2} / \mathrm{g}$ [13], [14]. This makes them useful for catalysis, sensing, optical applications, [14] and biomedical applications such as drug delivery, implant coating, scaffolds, hemostats, etc. [15]-[17]. The high SA also decreases the silica content limitation, meaning that $>65$ mol\% silica can be used, because the reactions has 100-1000x more surface area to react [18].

MBGs are not synthesized using conventional melt-quench methods. Instead, the sol-gel method is the most common way of making MBGs because of its ease and flexibility in tuning pore properties; composition, porosity, pore architecture and pore dimensions can all be tuned by the sol-gel approach [19].

\subsubsection{Sol-gel method for MBGs}

The sol-gel method is a means of connecting molecular building blocks to get the desired glass structure and composition [3]. A "sol" is a stable colloidal suspension of surfactants and glass precursors, usually an alkoxide [3]. For making silica based MBGs, tetraethylorthosilicate (TEOS) is usually the precursor. The colloids have a hydrophobic tail, facing the inside, and a hydrophilic 
head, facing the solvent. When the colloids aggregate together, they form a three-dimensional solid network which is the "gel" [3]. The sol is a stable suspension, and so for gelling to occur, the suspension needs to be perturbed. For producing MBGs, evaporation of the medium is used to get rid of the solvent and cause gelation. This process is called Evaporation Induced Self-Assembly (EISA) and is displayed in Figure 1.1 [20]. The slow evaporation of the solvent allows the colloids to aggregate into micelles, and the micelles to get closer to one another and bond via Van der Waals forces. As the hydrophilic solvent leaves, the micelles arrange themselves into pillar-like patterns to maximize hydrophobic-hydrophobic interaction [14].

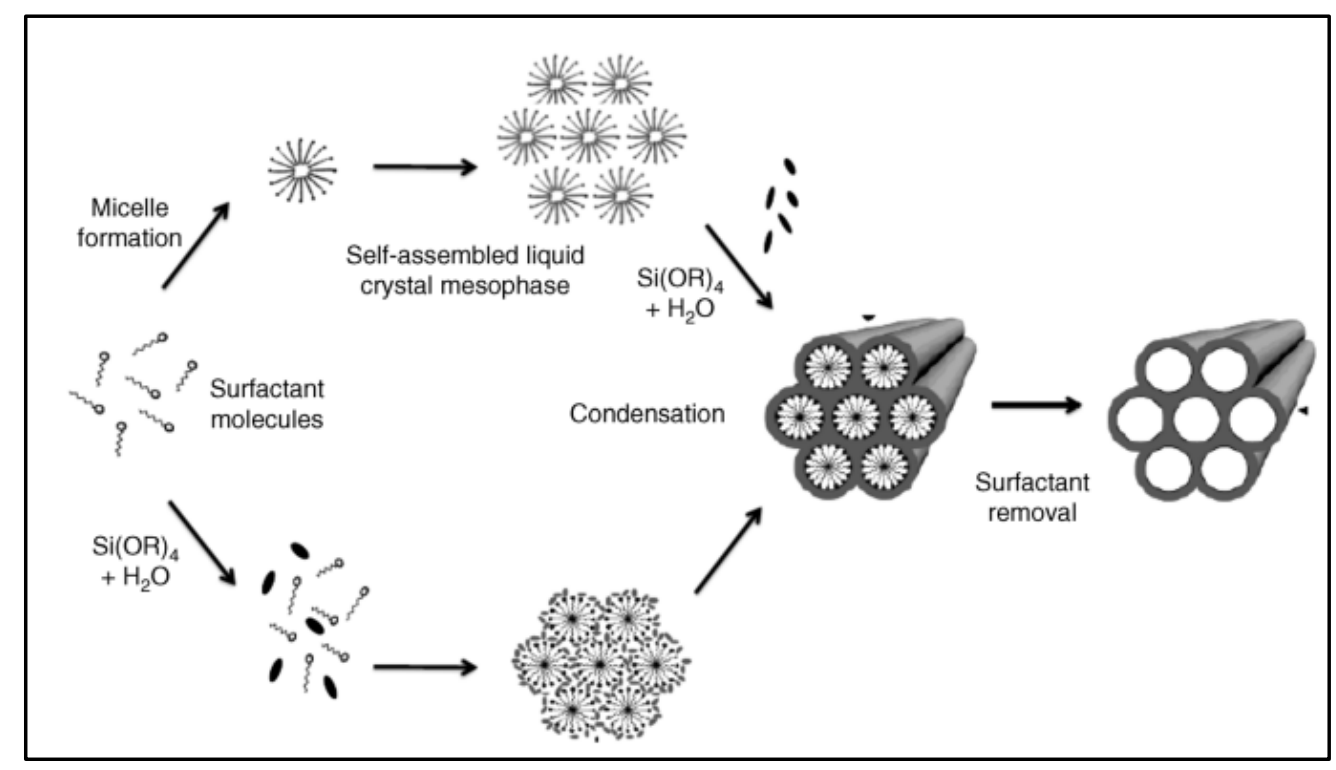

Figure 1.1: Representation of EISA method [3].

Once all the solvent is evaporated, the gel is calcined. This step removes the organic portion of the gel, leaving behind the silica and other added inorganic modifiers [3].

MBGs have potential for hemorrhage control. Therefore, it is important to know the properties of blood and how natural hemostasis occurs so that the mechanism by which MBGs work can be better determined.

\subsection{Blood}

Blood is a fluid connective tissue that makes up $\sim 8 \%$ of the body's weight. It is made up of $\sim 55 \%$ plasma, $\sim 45 \%$ red blood cells (RBCs) and $<1 \%$ of white blood cells (WBCs) and platelets [21]. The plasma is composed of proteins, electrolytes, nutrients, hormones, dissolved gases and waste 
in a water medium. The functions of blood can be grouped into three main categories: transport, regulation and protection [21]. Transportation of dissolved gases (oxygen and carbon dioxide), nutrients (glucose, amino acids, fats, vitamins and minerals), hormones and waste products (creatinine, bilirubin, nitrogenous products and drugs) are vital for regular body activity. RBCs are also key transports of oxygen and carbon dioxide within the body [21].

Temperature and osmotic regulation is also performed by blood [21]. Circulation of the blood keeps the entire body at nominal temperature, whereas plasma proteins keep osmotic balance between blood vessels and the extracellular fluid. Bicarbonate in the blood helps to regulate $\mathrm{pH}$ and dissolved gases. The various WBCs in the blood help protect the body from foreign species, and clean up dead cells and debris [21]. Any clinically significant amount of blood loss would have negative effects on organ function, physical sensation, immunity or all three.

\title{
1.4 Hemorrhage
}

Hemorrhage is the discharge of blood from a ruptured blood vessel. Bleeding can occur internally or externally and is classified depending on the volume of blood lost [22]. The World Health Organization has a 5 point grading scale to describe hemorrhage severity [23]:

\author{
Grade 0 - No bleeding \\ Grade 1 - Petechial bleeding \\ Grade 2 - Clinically significant mild blood loss \\ Grade 3 - Major blood loss requiring RBC transfusion \\ Grade 4 - Severe blood loss (or retinal/cranial bleeding) leading to fatality
}

Bodily homeostasis is sufficient to take care of Grade 1 bleeding (and some Grade 2 internal bleeding), but higher grades require medical intervention. For external bleeds, an average human body can lose up to $15 \%$ blood without negative side effects [24].

\subsection{Hemostasis}

Hemostasis is the process by which bleeding from a ruptured vessel is stopped [25]. This can be done physically, by sealing the vessel, or chemically, by speeding up the natural blood clotting process [26] which involves the blood gelling from a liquid. This occurs in three stages: vasoconstriction, platelet plug formation, and fibrin clot formation [27]. The final fibrin clot holds 
until the blood vessel walls are repaired. Vasoconstriction is the narrowing of the surrounding blood vessels [27]. This is important to limit the amount of blood flow from the injured vessel. It occurs by muscles contracting the local blood vessels. Collagen, from the walls of the injured vessel, is exposed and causes nearby platelets and Von Willebrand (vWF) factor to adhere to the injured site [28]. vWF is a glycoprotein found in blood plasma and within the endothelium of blood vessels. Its main purpose is binding to cells and molecules. In the plasma, it is usually found bound to another coagulation factor (VIII) thereby inhibiting the factor's function [29]. Releasing of the factor allows the factor to promote coagulation. vWF also binds to collagen and platelets to help platelets aggregate and activate platelets. Activated platelets are important for the second stage of coagulation [27]. The second stage of blood coagulation revolves around platelet plug formation, and is also called primary hemostasis [27]. Platelets adhered to the injury site get activated by the interaction of collagen with surface glycoproteins. When activated, they change form to express certain receptors, and release granules into the surroundings. The receptors interact with other platelets and help aggregate them together. The granules include adenosine diphosphate (ADP), serotonin and thromboxane A2 (TXA2) [21]. These cause more platelets to get attracted to the injury site (ADP), more vasoconstriction (serotonin and TXA2), and more granule release (TXA2). This positive feedback loop culminates in platelet plug formation [22]. The last stage of coagulation makes a stable clot from the platelet plug. This involves a series of enzymatic reactions known as the Coagulation Cascade [30], shown in Figure 1.2. In this cascade, an enzyme (denoted by a Roman numeral) interacts with a cofactor and becomes activated (appended lowercase "a"). The activated form then acts as a cofactor for another enzyme activation. This continues until fibrinogen gets activated into fibrin. Fibrin molecules polymerize and entrap platelets, RBCs and other blood species to form the fibrin clot, also known as a thrombus [27]. 


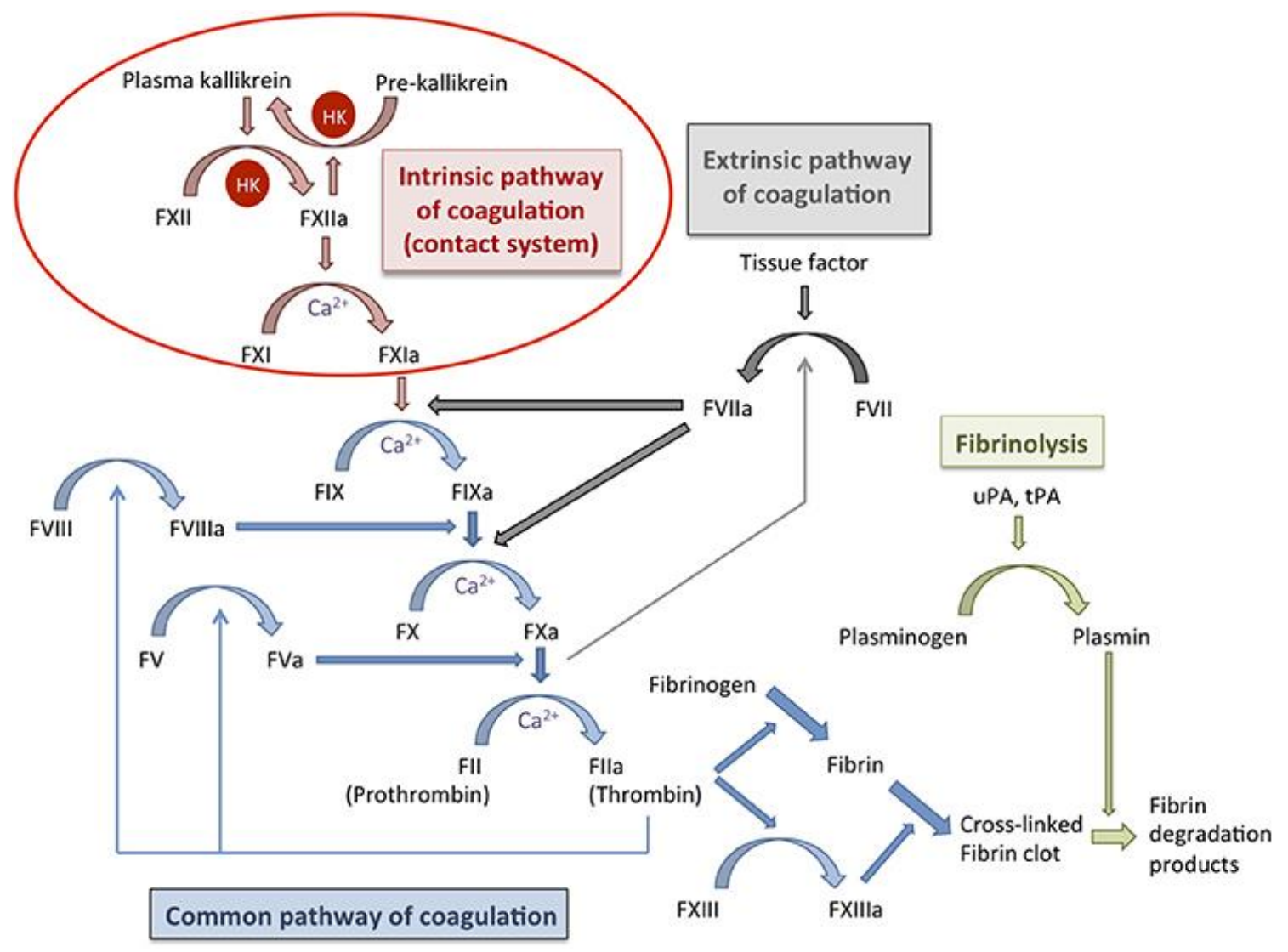

Figure 1.2: The blood coagulation cascade, including the intrinsic, extrinsic and common pathways [31].

The coagulation cascade can be initiated from two pathways: an intrinsic pathway (by foreign objects) and an extrinsic pathway (by internal tissue damage) [30]. Both pathways lead to a common pathway which culminates in fibrin formation. Once bleeding has ceased, endothelial cells and surrounding fibroblasts repair the vessel walls. Simultaneously, entrapped enzymes break down the fibrin clot from within while white blood cells get rid of the debris [30].

\subsection{Thrombosis}

The formation of a blood clot (thrombus) within a healthy blood ves sel is called thrombosis [22]. This can occur from overactivity of clotting factors or part of a blot clot getting loose and getting lodged in smaller blood vessels [22].

\subsection{Research significance}

Hemorrhage is one of the leading causes of death during surgery, trauma and in war [32], [33]. It is the leading cause of death after combat, and the second leading cause in civilian trauma centers 
[34]. In combat situations, approximately $50 \%$ of all deaths are caused by exsanguinating hemorrhaging, $20 \%$ of which are preventable [35]. Discounting wounds to the torso and head, which are typically lethal, wounds to the extremities account for over half of potentially preventable deaths [35]. In civilian settings, trauma from injuries is also a major cause of death. According to the Center for Disease Control, injuries are the leading cause of death in all age groups under the age of 45 , and has been for over the last decade [32]. As many as $20 \%$ of the deaths resulting from trauma could be prevented with optimal trauma care [36]. Even in the operating room, cardiac arrest and permanent disability of the nervous system from hemorrhage is the leading cause of death [37]. More than $80 \%$ of trauma deaths in an operating room are the result of hemorrhage [38].

In controlled situations, where there are medical staff and supplies available, it is possible to stop hemorrhaging with surgical means. However, when immediate intervention is not possible, there needs to be a means of hemostasis to prevent fatalities. Quick hemostasis not only increases the chances of survival, it also means lower demand for blood transfusion, lower chances of secondary diseases (e.g. sepsis, organ damage, and cardiac arrest) and faster healing times [33].

Hemostats are agents used to stop bleeding out from a damaged vessel. Conventional hemostats have fallen short in achieving ideal results due to their side effects [39]. As recommended by a panel of military experts [40], the ideal hemostat would be one that can:

- Achieve quick hemostasis in 2 minutes or less

- Be used on topical and deep wounds (arterial and/or venous)

- Be easily removed from the wound or biodegrade

- Not cause side effects (e.g. burns, allergic reactions, thrombosis)

- Be usable in various conditions (e.g. low temperature, wind, rain, etc.)

- Be safe and easy to administer, requiring no training

- Be cheap and have a long shelf life

Currently, there is no hemostat available that can fulfil all these criteria.

\subsection{Research goal and objectives}

The goal of this research is to synthesize a novel MBG that can function as an ideal hemostat. This goal will be broken down into a series of objectives: 
- Synthesis of MBGs with varying concentrations of tantalum

- Physical and chemical characterization of the MBGs

- In-vitro characterization of the MBG hemostatic efficacy with animal blood

- Cytotoxicity analysis of the MBGs

- Preliminary investigation of MBG hemostatic efficacy with human blood 


\section{Literature review}

The purpose of this literature review is to identify the current state of the art regarding hemostats. Commercially available hemostats will be discussed in Section 2.1 with their corresponding mechanisms of action and drawbacks. Potential hemostats will be discussed in Section 2.2, followed by a review of bioactive glasses in hemostasis in Section 2.3. Potential hemostats are those which are being researched but are not United States Food and Drug Administration (US FDA) cleared for clinical use.

\subsection{Commercial hemostatic agents}

Due to the substantial number of US FDA approved hemostats available on the market, only those with good viability and developed in the last two decades will be discussed. These can be further classified by a number of different parameters (composition, mechanism of action, cost, etc.) so for simplicity they will be classified by composition, being either inorganic or organic. A summary of the commercial agents can be found in Table 2.1 along with advantages and disadvantages.

\subsubsection{Inorganic hemostats}

Inorganic hemostats have two advantages over organic ones: they are generally cheaper to make, and their lack of human or animal proteins means they are easily sterilized and do not cause allergic reactions [39]. Broadly speaking, these hemostats can be classified into zeolite or clay based materials:

Zeolites are crystalline aluminosilicates that form three-dimensional structures of uniformly sized pores [41]. They contain other ions that charge balance the structure and allow for absorption of certain molecules based on size and charge; as such, they can act as molecular sieves. They accomplish hemostasis by absorbing water from the blood and concentrating coagulation factors. Two prominent zeolite hemostats are Advanced Clotting Sponge (ACS, Z-Medica, Connecticut, USA) and QuikClot (QC, Z-Medica, Connecticut, USA) granular powder. Both provided quick hemostasis in animal and human trials but have drawbacks. QC's rapid ion exchange when in contact with water (in blood) caused an exothermic reaction that burns the surrounding tissue; the small particle size of the powder and poor degradability also compromise its extraction from wound sites, and mean it could cause clots distinct from the wound site [33]. Derivative products package the zeolites in a mesh bag and lowered the exotherm, but still not sufficiently for arterial

bleeding [39]. ACS consists of larger beads of zeolite (compared to QC) packaged in gauze, but 
these also generated an exothermic reaction at the wound site [42]. A revised product, ACS+, was made pre-hydrated for slower cation exchange and less exotherm. This reduces burning but was not suitable for arterial bleeding [39] as the higher pressure from the artery causes the blood to wash away the product.

Clays are similar in composition to zeolites but are layered aluminosilicates that allow for water absorption into the layers, expanding the overall structure; as opposed to the rigid nature of zeolites [43]. Their hemostasis potential stems from this water absorption and the activation of the intrinsic pathway of blood coagulation from the negative surface charge [39]. Two prominent clay-based hemostats are QuikClot Combat Gauze (QCG, Z-Medica, Connecticut, USA) and WoundStat (WS, TraumaCure, Maryland, USA). QCG is supplied as kaolin impregnated into gauze and can be left up to 24 hours at the wound site. However, it did not show significantly faster hemostasis time compared to standard dressings and comparable blood loss has been reported with its use [44]. WS is applied in a granular form and expands to fill the wound cavity, making it easy to apply to any wound. However, it is not biodegradable and so must be removed from the site after hemostasis has occurred. This explains why WS caused thrombus formation away from the wound site from travelling particles, and local inflammation [45].

\subsubsection{Organic hemostats}

Organic hemostats are supplied in a very wide range of compositions and are best categorized by their mechanism of action. For simplicity, this will be divided into mechanical mechanisms, physiological mechanisms, and a combination of both. Hemostats that work under mechanical action include GelFoam (Pfizer, New York, USA), Avitene (Bard, New Jersey, USA), Surgicel (Johnson and Johnson, New Jersey, USA), and Arista (Bard, New Jersey, USA) which are made from porcine gelatin, bovine collagen, oxidized regenerated cellulose and polysaccharide spheres, respectively. The biggest issue with these hemostats is their swelling and potential for infection [26]. Swelling can cause compression of surrounding tissue, cutting off blood supply and causing necrosis [46]. Gelatin and collagen based hemostats could also cause allergic reactions due to being derived from animal products [47], whereas cellulose based products tend to cause inflammation from local pH changes [26].

Hemostats that work under physiological mechanisms are those that react with blood components directly. One such hemostat is the modified rapid deployment hemostat (mRDH, Marine Polymer 
Tech. Inc., Massachusetts, USA) and it works by causing local vasoconstriction, activation of platelets, and agglutination of RBCs [33]. It has shown great efficacy in controlling hemorrhage, however there have been cases of re-bleeding when the dressing is removed, and the cost is more than ten times most other hemostats [48]. Other physiologically activating hemostats are those that introduce thrombin, fibrin, fibrinogen, or a combination of the three to the wound site [26]. Examples of these include Thrombin-JMI (Pfizer, New York, USA), Tisseel (Baxter, Illinois, USA) and Evicel (Johnson and Johnson, New Jersey, USA). Hemostasis is usually fast and the products can be used for local or diffuse bleeding. The problem with these hemostats is that they are usually derived from animal or human plasma. This raises the concerns of allergic reactions, antibody creation and the spreading of viral or prion diseases [26], [33]. These hemostats also tend to be costlier, have a shorter shelf life and require specific preparation before usage, increasing the difficulty for use by hospital staff [26].

The last category of organic dressings is a combination of the previous two categories and mainly contains chitosan hemostats. Chitosan is a biodegradable, polysaccharide compound derived from shrimp shells and is a natural hemostatic agent [34]. It works by cross-linking RBCs and platelets to make a barrier around the wound site [44]. Initial hemostats made using chitosan (HemCon, Tricol Biomedical, Oregon, USA) were stiff and could not be applied to different wound sizes. However, newer products such as Celox (Celox, Crewe, UK) and ChitoFlex (Tricol Biomedical, Oregon, USA) solve this issue as they are powders and thin gauzes, respectively. Chitoflex has been shown to have increased incidences of re-bleeding upon removal of the dressing; Celox has shown good evaluation all around in hemostasis control [44]. 
Table 2.1: Summary of commercial hemostatic agents

\begin{tabular}{|c|c|c|c|}
\hline Hemostat & Composition & Advantages & Disadvantages \\
\hline ACS/ACS+ & Inorganic - zeolite & $\begin{array}{l}\text { Quick hemostasis initiation } \\
\text { Cheap and easy to use }\end{array}$ & $\begin{array}{l}\text { Causes burns } \\
\text { Not suitable for arterial } \\
\text { bleeding }\end{array}$ \\
\hline QuikClot & Inorganic - zeolite & $\begin{array}{l}\text { Quick hemostasis initiation } \\
\text { Cheap and easy to use }\end{array}$ & $\begin{array}{l}\text { Causes burns } \\
\text { Hard to remove } \\
\text { Not suitable for arterial } \\
\text { bleeding }\end{array}$ \\
\hline QCG & Inorganic - clay & $\begin{array}{l}\text { Can be left at wound site } \\
\text { Cheap and easy to use }\end{array}$ & Slow hemostasis initiation \\
\hline Woundstat & Inorganic - clay & $\begin{array}{l}\text { Expands to fill cavity } \\
\text { Cheap and easy to use }\end{array}$ & $\begin{array}{l}\text { Causes thrombus formation } \\
\text { and inflammation }\end{array}$ \\
\hline GelFoam & Organic-gelatin & $\begin{array}{l}\text { Cheap and easy to use } \\
\text { Biodegradable/compatible }\end{array}$ & $\begin{array}{l}\text { Swelling/tissue necrosis } \\
\text { Possible allergic reactions }\end{array}$ \\
\hline Avitene & Organic - collagen & $\begin{array}{l}\text { Cheap and easy to use } \\
\text { Biodegradable/compatible }\end{array}$ & $\begin{array}{l}\text { Swelling/tissue necrosis } \\
\text { Possible allergic reactions }\end{array}$ \\
\hline Surgicel & Organic - cellulose & $\begin{array}{l}\text { Cheap and easy to use } \\
\text { Biodegradable/compatible }\end{array}$ & $\begin{array}{l}\text { Swelling/tissue necrosis } \\
\text { Inflammation }\end{array}$ \\
\hline Arista & Organic - polysaccharide & $\begin{array}{l}\text { Cheap and easy to use } \\
\text { Biodegradable/compatible }\end{array}$ & Swelling/tissue necrosis \\
\hline $\mathrm{mRDH}$ & $\begin{array}{l}\text { Organic - } \\
\text { protein/polymer }\end{array}$ & $\begin{array}{l}\text { Quick hemostasis } \\
\text { Useful for any bleeding types } \\
\text { Useful in coagulopathies }\end{array}$ & $\begin{array}{l}\text { Very expensive } \\
\text { Re-bleeding in some cases }\end{array}$ \\
\hline $\begin{array}{l}\text { Thrombin- } \\
\text { JMI }\end{array}$ & $\begin{array}{l}\text { Organic - enzyme } \\
\text { (thrombin) }\end{array}$ & $\begin{array}{l}\text { Quick hemostasis } \\
\text { Useful in coagulopathies }\end{array}$ & $\begin{array}{l}\text { Longer prep time to use } \\
\text { Possible allergic reaction }\end{array}$ \\
\hline Tisseel & Organic - protein (fibrin) & $\begin{array}{l}\text { Quick hemostasis } \\
\text { Useful in coagulopathies }\end{array}$ & $\begin{array}{l}\text { Longer prep time to use } \\
\text { Possible allergic reaction }\end{array}$ \\
\hline Evicel & Organic - protein (fibrin) & $\begin{array}{l}\text { Quick hemostasis } \\
\text { Useful in coagulopathies }\end{array}$ & $\begin{array}{l}\text { Longer prep time to use } \\
\text { Possible virus transmission }\end{array}$ \\
\hline HemCon & Organic - chitosan & Biodegradable/compatible & $\begin{array}{l}\text { Stiff and specific size } \\
\text { Debatably faster hemostasis }\end{array}$ \\
\hline Chitoflex & Organic - chitosan & Biodegradable/compatible & Re-bleeding in some cases \\
\hline Celox & Organic - chitosan & Biodegradable/compatible & Debatably faster hemostasis \\
\hline
\end{tabular}




\subsection{Potential hemostatic agents}

This section will look at new materials being researched as potential hemostatic agents with special focus on the in-vivo data from animal or human trials. Due to the volume of information available, this review will focus on advances in the last twenty years in the field. A summary of the materials can be found in Table 2.2 along with advantages and disadvantages of each relative to regular physiological hemostasis.

\subsubsection{Hydrogel based hemostats}

Hydrogels are polymeric materials capable of storing large volumes of water relative to their mass. The polymeric components can be functionalized to react specifically with blood components, while the structure can absorb water and concentrate coagulation factors [49]. Murakami et al. made one such hydrogel containing cross-linkable polymeric micelles [50]. The micelles adhered to host tissue and the cross-linking caused gelation of the micelles and blood components. Using a liver prick mouse model, the hydrogel was shown to reduce bleeding significantly $(p=0.002)$, even out-performing Tisseel (Baxter, Illinois, USA) $(p=0.07)$. However, the clot strength in the mouse model was poor and the tissue-adhesive properties needed to be improved so that the hydrogel isn't washed away before sufficient clotting occurred. In work performed by Mirzakhanian et al., nanoparticles of silica and zeolites were embedded into acrylic-starch hydrogels (separately) to activate the intrinsic pathways of coagulation while concentrating coagulation factors [51]. Using a femoral artery rat model, they showed that the hydrogel nanocomposite (HNC) arrested the bleeding and the rat survived post-operatively for at least seven days. The group also conducted a hemolysis assay, to determine whether RBCs are lysed in the presence of the material, and found that the HNCs were not hemolytic. The major drawbacks with this work are the lack of test repetition (only one rat was reported) and the major swelling of the HNCs (> $24000 \%$ by mass) which could lead to post-operative complications in surgical situations.

Annabi et al. created a sealant using the bioelastomer tropoelastin, methacrylating it, and crosslinking it to form a hydrogel [52]. The hydrogel has elastic and adhesive properties, is non-toxic, and biodegradable. It was applied to a rat artery incision model in which it out-performed Evicel (Johnson and Johnson, New Jersey, USA) significantly $(p<0.01)$. The burst pressure of the sealed part also exceed that of regular blood pressure [53]. Though this may work as a hemostat for 
incision type wounds, it could not be used for larger wounds where the ends of the tissue are further apart.

\subsubsection{Synthetic hemostats}

These materials are lab-made but are analogous to materials/structures found in the body. They do not have the issue of disease transmission as they don't have human markers. Bertram et al. created synthetic platelets by functionalizing Arg-Gly-Asp amino acids on polymer nanoparticles [54]. They were used in a rat femoral artery injury model where they were administered intravenously before the injury was made. Mice showed a significant decrease in hemostasis time ( $50 \%)$ with the synthetic platelets compared to the control groups. It was even significantly more effective than administration of recombinant factor VIIa, a chemical used to treat uncontrollable hemorrhaging [54]. The issue with this hemostat is that it must be administered before the injury is made. The group also tested the bleeding time with synthetic platelet administration after the injury and the prognosis was worse than the control group.

Another synthetic material is called TDM-621 and consists of sixteen amino acids that selfassemble to make nanofibers. These fibers form a network in physiological solutions, causing gelation and hemostasis when used in wounds [55]. The material later name PuraStat@ (3-D Matrix Inc., Tokyo, Japan), has undergone numerous clinical trials and is on the precipice of FDA approvals. The trials include cardiovascular surgery, digestive surgery, multiple studies of digestive endoscopy and endonasal surgery, reporting hemostatic efficacy of $>87 \%$ with accelerated healing and minimal adverse effects [56]. An issue that may be present with this product is that it may not work with higher pressure arterial bleeding. The gel would get washed away or get too diffused to have a proper hemostatic effect.

\subsubsection{Natural hemostats}

Besides chitosan, there are other natural compounds in animals and plants that have been exploited for their hemostatic capabilities. Ankaferd Blood Stopper® (ABS, Trend Teknoloji Ilaç AS, Istanbul, Turkey) is the commercial hemostat made from five plants: Thymus vulgaris, Glycyrrhiza glabra, Vitis vinifera, Alpinia officinarum and Urtica dioica and was historically used for centuries in Turkey for treating hemorrhage [57]. The exact mechanism of hemostasis is unknown but a protein network is known to form that aggregates RBCs. In a rat model of aortic bleeding, an ABSsoaked tampon showed significantly shorter reduction in bleeding times compared to regular gauze 
tampons $(p<0.001)$. There was no necrosis of tissue, and the inflammatory response was similar in both groups [58]. However, there was discolouration of some WBCs in the ABS group indicating a foreign body response. More long-term studies need to be done to verify the extent of the effects.

Batroxobin, the venomous compound of snake venom, is also reported to have hemostatic activity. The compound catalyzes fibrinogen into insoluble fibrin, thereby speeding up clot formation [59]. In a study by You et al. a mouse liver injury model and a rat femoral artery model were tested using an adhesive soaked with batroxobin [59]. With the liver injury model, only the highest tested dose of $50 \mathrm{NIH} \mathrm{U/mL} \mathrm{(National} \mathrm{Institute} \mathrm{of} \mathrm{Health} \mathrm{Units)} \mathrm{showed} \mathrm{significant}(p<0.05)$ reduction of blood loss compared to the adhesive alone. With the femoral artery model, similar results were seen for total blood loss, however, the bleeding was arrested faster with batroxobin compared to the plain adhesive. Another positive note was the significantly less occurrences of re-bleeding with batroxobin [59]. Kumar et al. reported similar results with regard to concentrations required to achieve good hemostasis [60]. In their work, batroxobin is loaded into a hydrogel and tested in a rat liver incision model with and without heparin (an anticoagulant). Batroxobin alone was not able to stop the bleeding but with the hydrogel it proved to have the fastest hemostasis time in regular and heparinized rats, outperforming GelFoam (Pfizer, New York, USA) and Puramatrix (3-D Matrix Inc., Tokyo, Japan) [60]. From these studies it is apparent that batroxobin requires some carrier matrix to physically stop bleeding while it works on fibrinogen conversion. Unfortunately, it seems that the working dose $(\sim 50 \mathrm{NIH} \mathrm{U} / \mathrm{mL})$ is close to the dose at which cell viability starts being affected (60 NIH U/mL) [59].

Keratin is an insoluble protein found in appendageal structure (hair, nails, horns, etc.). These proteins can self-assemble into filaments, which can then rearrange into higher ordered nanostructures to make up tissue [61]. It also has good cell adhesion properties and is highly biocompatible. Aboushwareb et al. used keratin from human hair to create a hemostatic hydrogel. It works by binding to the local tissue and causes aggregates of RBCs; the binding is strong enough not to get washed away by heavy bleeding. A rabbit liver injury model showed that keratin treatment reduced blood loss significantly more than the control and the commercial HemCon (Tricol Biomedical, Oregon, USA). However, it performed on par with commercial QuikClot (ZMedica, Connecticut, USA) [62]. 
Table 2.2: Summary of potential hemostatic agents being researched

\begin{tabular}{|c|c|c|c|}
\hline Ref. & Composition & Advantages & Disadvantages \\
\hline [50] & $\begin{array}{l}\text { Hydrogel }+ \text { crosslinking } \\
\text { micelles }\end{array}$ & Quick gelation of blood & Poor clot strength \\
\hline [51] & $\begin{array}{l}\text { Hydrogel }+ \\
\text { nanosilica/zeolite }\end{array}$ & $\begin{array}{l}\text { Non-hemolytic } \\
\text { Quick hemostasis } \\
\text { Natural }\end{array}$ & $\begin{array}{l}\text { Extreme swelling of } \\
\text { composites }\end{array}$ \\
\hline $\begin{array}{l}{[52],} \\
{[53]}\end{array}$ & $\begin{array}{l}\text { Hydrogel sealant from } \\
\text { bioelastomer tropoelastin }\end{array}$ & $\begin{array}{l}\text { good elasticity and adhesion } \\
\text { Biodegradable/compatible }\end{array}$ & Not good for wide wounds \\
\hline [54] & Synthetic platelets & Very quick hemostasis & $\begin{array}{l}\text { Needs to be administered } \\
\text { prior to bleeding }\end{array}$ \\
\hline $\begin{array}{l}{[55],} \\
{[56]}\end{array}$ & Self-assembling amino acid & $\begin{array}{l}\text { Forms nanofibers to make a gel } \\
\text { Undergone clinical trials with } \\
\text { good results }\end{array}$ & $\begin{array}{l}\text { May not work with deep } \\
\text { wounds or arterial bleeds }\end{array}$ \\
\hline $\begin{array}{l}{[57],} \\
{[58]}\end{array}$ & Ankaferd Blood Stopper & $\begin{array}{l}\text { Similar material has been used } \\
\text { for centuries effectively } \\
\text { Quick hemostasis } \\
\text { Cheap }\end{array}$ & $\begin{array}{l}\text { Caused some foreign body } \\
\text { response } \\
\text { Exact mechanism unknown }\end{array}$ \\
\hline $\begin{array}{l}{[59],} \\
{[60]}\end{array}$ & Batroxobin (snake venom) & $\begin{array}{l}\text { Independent of most } \\
\text { coagulopathies } \\
\text { Less re-bleeding }\end{array}$ & $\begin{array}{l}\text { Needs a matrix/carrier } \\
\text { material } \\
\text { Could be lethal }\end{array}$ \\
\hline $\begin{array}{l}{[61],} \\
{[62]}\end{array}$ & Keratin hydrogel & $\begin{array}{l}\text { Cheap } \\
\text { Can be used for arterial bleeding }\end{array}$ & $\begin{array}{l}\text { On par performance with } \\
\text { QuikClot }\end{array}$ \\
\hline
\end{tabular}

\subsection{Bioactive glasses for hemostasis}

Silicate materials are researched often because their inherent negatively charge surface is ideal for intrinsic activation of coagulation [30]. They are used in many forms including nanoparticles [51], BGs [63], MBGs [17], [64], xerogels [65], diatoms [66], etc. Hemostatic activity for BGs was first reported by MacNeill et al. while comparing various osseous grafts in rabbit tibial osteotomies [67]. They found that BGs and autogenous bone stopped bleeding quickly after the surgery 
compared to HA or negative controls. Reporting hemostasis time was not the intention of the study, so it was only qualitatively discussed. Chen et al. also tested the bone regeneration capabilities of a BG composite verses bone wax and a negative control, in rabbits [68]. However, they quantitatively measured the hemostasis effect by measuring blood loss after the procedure and found more than ten times reduction in blood loss versus the control. There was no significant difference compared to the bone wax. In 2006, a study was done by Ostomel et al. to specifically look at the hemostatic effect of BGs [69]. They used Thromboelastography (TEG, described in Section 3.5.2) to compare BGs with varying Si:Ca ratios and found that higher Si:Ca ratios increase hemostatic activity proportionally. They also varied the porosity and found that porous BGs perform better than non-porous ones [69]. However, the authors do not mention what type of blood is used or the TEG protocol followed. This could have introduced error depending upon how the BGs were introduced into the TEG cups or the state of the blood (species it came from, age, etc.). Hemolysis tests were not conducted either.

\subsubsection{Mesoporous bioactive glasses for hemostasis}

MBGs are showing promising results in the field due to their higher surface area and pore volume relative to conventional BGs. Hu et al. synthesized MBGs with silver (Ag) that added antibacterial effects. At just $0.02 \mathrm{wt} \% \mathrm{Ag}, 75 \%$ and $99 \%$ of $E$. coli growth was inhibited within 1 and 12 hours respectively. From a rabbit skin injury model, it was found that MBGs performed significantly better than BGs of similar chemical composition and both performed better than the control group; hemostasis times were $27 \pm 2 \mathrm{~s}, 86 \pm 3 \mathrm{~s}$, and $193 \pm 8 \mathrm{~s}$ for the MBGs, BGs and control group respectively [64]. Though cytotoxicity studies generated acceptable results, hemolytic studies should be conducted to see whether the glasses cause hemolysis of the RBCs. A similar material was developed by Dai et al. but with more Ca present [70]. They report a surface area of $919 \mathrm{~m}^{2} / \mathrm{g}$, which is exceptional even for MBGs (usually in the $300-500 \mathrm{~m}^{2} / \mathrm{g}$ range like $\mathrm{Hu}$ et al. previously mentioned). In a rabbit femoral artery injury model, powder and granule AgCaMBGs reduced hemostasis time from $342 \pm 25 \mathrm{~s}$ (control) to $19 \pm 1 \mathrm{~s}$ and $16 \pm 2 \mathrm{~s}$, respectively. Blood loss was even reduced by $27 \%$ and $37 \%$ for powder and granule samples [70]. The rabbits were sacrificed one hour after experiments and so long-term effects (thrombus formation, hemolysis, foreign body response, etc.) is not known. Pourshahrestani et al. produced gallium (Ga) containing MBGs and showed their hemostatic potential as powders and in chitosan composite scaffolds [17], [71]. In powder form, the Ga-MBGs had most hemostatic potency at $1 \%$ Ga incorporation, showing 
significantly lower activated partial thromboplastin (APTT) time, significantly higher platelet adhesion and better thrombogenicity compared to MBGs without Ga [17]. At 50 wt.\% loading of the $1 \%$ Ga-MBGs into chitosan scaffolds, this new composite had significantly better thrombogenicity and platelet adhesion compared to plain chitosan and the commercial Celox (Celox, Crewe, UK) [71]. In both cases, in vivo trials and hemolysis tests were not conducted.

\subsection{Scientific Rationale}

The current research formulates tantalum (Ta) containing MBGs and investigates their potential in hemostasis. Silica MBGs were chosen as the carrier because of their structural properties (porous, highly ordered, over $200 \mathrm{~m}^{2} / \mathrm{g} \mathrm{SA}$ ) [20], which allow for concentration of coagulation factors while the negative surface charge of silica activates the intrinsic pathway of coagulation [70]. Calcium ions are used within the glass because they can elute to promote coagulation. Phosphorous was added to maintain a $\mathrm{Ca} / \mathrm{P}$ ratio that is similar to HA (10:6 or 1.667) [63]. Ta was chosen to be investigated for several reasons. Firstly, it has been proven to increase bioactive glass dissolution [72], [73]. Secondly, it also increases cell viability when used in bioactive glasses compared to non Ta containing counterparts [73]. Thirdly, it has been previously used in hemostatic applications [74]-[76]: Ta oxide, containing low amounts of iron, has been previously reported to aid in hemostasis and wound healing [74], anodized Ta coated glass can increase fibrinogen conversion [75] and Ta has been used as a hemostatic clip in the past [76]. To the author's knowledge, incorporation of Ta into MBGs has not been previously reported. This research aims to understand the effects, if any, of Ta on hemostasis and its behavior in bioactive glasses. 


\section{Materials and Methods}

\subsection{Materials}

Reagent grade triblock copolymer P123, calcium nitrate tetrahydrate ( $\geq 99.0 \%)$, triethyl phosphate ( $\geq 99.8 \%$, TEP), tetraethyl orthosilicate (98\%, TEOS), tantalum (V) ethoxide (99.98\%), and ethanol were used. Reagent grade hydrochloric acid was diluted to $0.5 \mathrm{M}$ using distilled water. All reagents were obtained from Sigma Aldrich, Oakville, Canada. P123 was the chosen surface directing agent used to make the mesoporous structure because it yields well ordered, 2D hexagonal channels [20]. Arista ${ }^{\circledR}$ was purchased from C. R. Bard Inc. (New Jersey, USA) to use as a control for the hemostasis model.

\subsection{Synthesis}

MBGs were synthesized with incremental tantalum content, at the expense of silicon, according to Table 3.1. Calcium and phosphorous, incorporated to increase bioactivity through apatite formation, are kept constant through all the samples.

Table 3.1: Compositions of synthesized mesoporous bioglasses (mol\%).

\begin{tabular}{ccccc}
\hline Sample code & Ta & Si & Ca & P \\
\hline MTa-0 & 0 & 80 & 15 & 5 \\
MTa-0.5 & 0.5 & 79.5 & 15 & 5 \\
MTa-1 & 1 & 79 & 15 & 5 \\
MTa-5 & 5 & 75 & 15 & 5 \\
MTa-10 & 10 & 70 & 15 & 5 \\
\hline
\end{tabular}

Synthesis of MBGs was performed using the method outlined by Yan et. al. [20]. Typically, 4g of P123 and $1.4 \mathrm{~g}$ of calcium nitrate tetrahydrate were dissolved in $76 \mathrm{~mL}$ of ethanol. In a separate graduated cylinder, $1 \mathrm{~mL}$ of $0.5 \mathrm{M}$ hydrochloric acid and appropriate amount of TEOS was allowed to react for the acid-catalyzed hydrolysis of TEOS. Then $0.68 \mathrm{~mL}$ TEP and appropriate amount of tantalum (V) ethoxide was added to the ethanol solution. Lastly, the TEOS-acid solution was poured into the ethanol solution.

The solution was covered and stirred overnight. It was then transferred to a petri dish for 5 days to allow for the EISA process. The EISA-derived gel was then calcined at $650^{\circ} \mathrm{C}$, holding for 6 
hours. The ramp rate used for the furnace was $1^{\circ} \mathrm{C} / \mathrm{min}$. The resultant MBGs were ground, and sieved with a $45 \mu \mathrm{m}$ mesh.

\subsection{Physical characterization}

\subsubsection{X-ray diffraction}

Wide-angle $\mathrm{x}$-ray diffraction (WAXRD) was carried out to determine the presence of any crystal formation in the glass. Wide angle diffraction patterns were collected using a Philips PW3710 Xray diffractometer (Phillips, Holland) with a $\mathrm{Cu}$ source from $5^{\circ}$ to $160^{\circ}(2 \theta)$, at a step size of $0.1^{\circ}$. A generator voltage of $45 \mathrm{kV}$ and a tube current of $20 \mathrm{~mA}$ were employed.

Small angle $\mathrm{x}$-ray diffraction (SAXRD) was carried out to confirm whether ordered mesoporous channels were present. It was carried by Anisur Rahman at the University of Waterloo (Waterloo, Canada). SAXRD patterns were collected using an Anton Parr SAXS diffractometer (Anton Paar, Austria) with a $\mathrm{Cu}$ source from $0.2^{\circ}$ to $10^{\circ}(2 \theta)$, at a step size of $0.04^{\circ}$. A generator voltage of 40 $\mathrm{kV}$ and a tube current of $50 \mathrm{~mA}$ were employed.

\subsubsection{Transmission electron microscopy}

Transmission electron microscopy was carried out on a Hitachi HT-7700 (Hitachi, Japan), to visualize the structure of the nano-channels within the glass. Samples were embedded in modified Spurr's resin (Electron Microscopy Sciences, Pennsylvania, USA), ultra-microtomed to 100nm thick slices, and then put on copper grids for imaging. Imaging was carried out at $80 \mathrm{kV}$ and an emission current of $\sim 10 \mu \mathrm{A}$.

\subsubsection{Nitrogen adsorption analysis}

Textural properties were quantified by surface area measurements, carried out by nitrogen gas adsorption in a Micromeritics Gemini VII 2390 gas adsorption analyzer (Micromeritics, Georgia, USA); it was done by Dr. Owen Clarkin (Mechanical and Manufacturing Engineering, Dublin City University, Ireland). The surface area was then calculated using Brunauer, Emmett and Teller (BET), and pore size distribution and pore volume were estimated using the Barrett-JoynerHalenda (BJH) schema. 


\subsection{Chemical characterization}

\subsubsection{Energy dispersive $x$-ray spectroscopy}

A JEOL 6380LV scanning electron microscope (JEOL, Massachusetts, USA) equipped with Oxford energy dispersive x-ray spectroscopy (EDS) was used to examine the chemical composition of each sample. A $1 \mathrm{~cm} \mathrm{Cu}$ sample holder with double sided carbon tape was pressed onto powder samples and placed into the SEM for analysis. A generating voltage of $20 \mathrm{kV}$ was used.

\subsubsection{X-ray photoelectron spectroscopy}

X-ray photoelectron spectroscopy (XPS) was conducted to get compositional data and find the binding energy changes of the samples. It was done on a K-Alpha XPS system (Thermo Fisher Scientific, Massachusetts, USA) by Peter Broderson at the University of Toronto (Toronto, Canada). Monochromated Al K-Alpha x-rays were used for analysis, with a spot size of $400 \mu \mathrm{m}$. Charge compensation was achieved utilizing a low energy flood of electrons and ions under $\sim 5 \times 10^{-}$

${ }^{8}$ mbar vacuum. Residual pressure was from argon associated with operation of a charge compensation source. The survey spectrum was acquired in a high pass energy $(200 \mathrm{eV})$, low point-density (1 point/eV) scanned mode. Regional spectra, used to determine relative atomic composition, as well as for determination of chemical information, was acquired in a low pass energy $(50 \mathrm{eV})$, high point-density $(0.1 \mathrm{eV}$ spacing) scanned mode.

\subsubsection{Fourier transform infrared spectroscopy}

Fourier transform infrared spectroscopy was carried out on the powder samples using an ATRiS50 FTIR (Thermo Scientific, Massachusetts, USA). This was done to understand the types and relative intensities of the bonds present in the samples. Spectra were collected from $400-1500 \mathrm{~cm}^{-}$ ${ }^{1}$ with $0.25 \mathrm{~cm}^{-1}$ resolution.

\subsubsection{Zeta potential}

The zeta potential of a material is the electrical potential that develops at the interfacial double layer from immersing the material in a solution. Zeta potential of the glasses were measured using a zeta potential analyzer (Zetasizer-Nano Series, Malvern Instruments Ltd., U.K). A dilute polystyrene latex solution was used as a calibration material with DI water as the medium. Disposable folded capillary cells were used during the measurement. Each sample was run $n=3$ times, with 3 measurements taken for each run. 


\subsection{In-vitro characterization}

\subsubsection{Ion release}

Ion release was conducted in deionized water (DI) and analyzed using inductively coupled plasmaoptical emission spectroscopy (ICP-OES). $50 \mathrm{mg}$ of sample was placed in a micro-centrifuge tube containing $1 \mathrm{~mL}$ deionized water. After the appropriate time intervals (15, 30 and $60 \mathrm{~min})$, samples were centrifuged at $10000 \mathrm{rpm}$ for $2 \mathrm{~min}$. The supernatant was collected and diluted to conduct analyses; $\mathrm{n}=3$ samples were collected.

Chemical compositions of the collected samples were analyzed using ICP-OES, performed on an Optima 7300 DV ICP-OES (Perkin Elmer, Massachusetts, USA). Calibration standards for silicon, calcium and phosphorus were prepared from a $1000 \mathrm{ppm}$ stock solution. For silicon sample 1, 5, 10 and 25 ppm were used as calibration standards. For calcium and tantalum 0.5, 1, 5, and $10 \mathrm{ppm}$, and for phosphorous $0.1,0.5,1,5 \mathrm{ppm}$ calibration standards were used. In all cases, DI water was used as the blank. Each sample was measured three times by the machine.

\subsubsection{Thromboelastography}

In-vitro clot characteristics are clinically measured using a thromboelastography machine. To get similar data, thromboelastography (TEG) was carried out on a TEG® 5000 Thrombelastograph ${ }^{\circledR}$ (Haemonetics Corporation, Massachusetts, USA) analyzer. Two cups were connected to individual channels to compare the effects of a sample to a blank control. Mouse blood was used for the tests, following approval from the research ethics board of St. Michael's Hospital, Toronto, Canada (reference number: ACC 739). 6-8 week old WT c57bl/6 mice were housed at the hospital facilities and given unrestricted access to food and water. Prior to blood draw, mice were anesthetized via intraparitoneal injection with $10 \mu \mathrm{L} / \mathrm{g}$ bodyweight of tribromoethanol (Avertin). An incision was made in the abdomen and skin pulled aside to reveal the organs. The organs were carefully moved out of the way for access to the inferior vena cava. Blood was drawn with a $25 \mathrm{G}$ $\mathrm{x} 1 / 2$ " needle into a citrated vacutainer ( $3.2 \%$ sodium citrate). $340 \mu \mathrm{L}$ of blood was transferred to each of the two TEG® cups, followed by $20 \mu \mathrm{L}$ of calcium chloride to return the calcium content to blood. $20 \mathrm{mg}$ of the MTa sample was added to one of the cups while the other was the control. The machine was run with maintaining the samples at $37{ }^{\circ} \mathrm{C}$. Each mouse had enough blood for one sample and control run (two TEG ${ }^{\circledR}$ cups); $n=5$ repetitions were carried out for all the MTa samples and Arista®. 


\subsubsection{Hemostasis mouse model}

To evaluate the hemostatic performance of the MBGs, a tail-cut model was used. The trials were approved by the St. Michael's Hospital research ethics board (St. Michael's Hospital, Toronto, Canada, reference: ACC739). 6-8 weeks old, wild type c57bl/6 mice were housed at the hospital facilities and given unrestricted access to food and water. Prior to tail transection, mice were anesthetized via intraperitoneal injection with $10 \mu \mathrm{L} / \mathrm{g}$ bodyweight of tribromoethanol (Avertin). Tail transection was performed $5 \mathrm{~mm}$ from the tip with a scalpel. For all treatment samples, the injury was coated evenly with samples of glass or Arista ${ }^{\circledR}$ and mice were then placed on top of a platform with the tail hanging over the edge. The time was recorded, and the tail dabbed onto blotting paper every 15 seconds (from transection) until bleeding ceased. The time required for bleeding to stop was reported as the bleeding time. Mice were randomly treated with MBG samples $(n=5-10$ for each $M B G)$, Arista ${ }^{\circledR}(n=5)$ or no treatment $(n=9)$. Since the mice age spanned a couple weeks between the start and end of testing, extra mice were tested intermittently without treatment to see whether the age caused a variation in the data. All the data fell within the initial range measured for $n=5$. Tests of the MTa- 0 material were repeated $(n=5)$ because they initially showed no significant difference from absence of treatment, and a re-trial was performed to ensure no experimental error had taken place. Results were similar to the first set of tests.

\subsubsection{Hemolysis test}

A hemolysis test was performed to determine whether MBG powders would cause lysis of the RBCs. Lysis would cause hemoglobin levels in the plasma to rise proportionately, which can be detected photometrically by measuring the change in absorbance at $\sim 540 \mathrm{~nm}$ wavelength. Permissions for testing human blood were obtained from Ryerson University research ethics board (Ryerson University, Toronto, Canada, reference: REB 2018-190). Human blood anticoagulated with sodium ethylenediaminetetraacetic acid (EDTA) was obtained (Cedarlane, Burlington, Canada) for use. $2.5 \mathrm{mg}$ of MBG samples were placed into microcentrifuge tubes. $500 \mathrm{~mL}$ of blood was added to the tubes and the tubes inverted gently 4-5 times for the powders to mix. This was then incubated for $60 \mathrm{~min}$. The tubes were then centrifuged at $2500 \mathrm{G}$ for $10 \mathrm{~min}$ and $200 \mu \mathrm{L}$ of the supernatant (plasma) was removed and put into cuvettes. $1800 \mu \mathrm{L}$ of phosphate buffered saline (PBS) was added to the cuvettes to ensure the appropriate fluid volume and dilution for the spectrophotometer. All five MTa samples were tested along with a negative control of only blood, $(\mathrm{n}=5)$. A positive control was made by adding $10 \mathrm{~mL}$ of DI water into $4 \mathrm{~mL}$ of blood. After 60 
min of incubation, the sample was centrifuged at $2500 \mathrm{G}$ for $10 \mathrm{~min}$ and the supernatant collected. $100 \%, 50 \%, 25 \%, 10 \%$ and $1 \%$ dilutions were made to create a fitting curve of the samples.

Spectrophotometry was carried out on a Shimadzu UV-3600 UV-VIS-NIR Spectrophotometer (Shimadzu Corp., Kyoto, Japan) at $541 \mathrm{~nm}$ in absorbance mode. PBS in a cuvette was used as the baseline to remove the signal from those. Initial dilutions for the positive control exceeded the machine's detection limit and so all samples and controls were diluted 1:1 with PBS.

\subsection{Cytotoxicity}

\subsubsection{Cytotoxicity assay}

A standard MTT (3-(4,5-dimethylthiazol-2-yl)-2,5-diphenyltetrazolium bromide) assay was used to determine cytotoxicity. The assay was conducted by Loraine Chu at St. Michael's Hospital (Toronto, Canada). Live cells can metabolize the MTT dye into insoluble formazan. The formazan is dissolved into a coloured solution and the absorption of the solution measured. The absorption is directly related to the concentration of formazan, which is directly related to the amount of metabolic activity (i.e. the number of live cells).

Three doses (1, 3, and $5 \mathrm{mg}$ ) of each MTa glass powders were weighed (Mettler Toledo XP26, Max $22 \mathrm{~g}, \mathrm{~d}=0.001 \mathrm{mg}$ ) and sprinkled on the bottom of wells. Bovine fibroblasts cells, isolated from cow ligaments according to procedure in Appendix $\mathrm{C}$ were then seeded into the well plates at a density of 10,000 cells per well, in Dulbecco's modified Eagle medium (DMEM) supplemented with $10 \%$ fetal bovine serum (FBS), and cultured for $72 \mathrm{~h}$. Fibroblasts were chosen because of their prominence in blood; bovine fibroblasts were specifically used because they being culture for another project and so were readily available. The MTT was added in an amount equal to $10 \%$ of the culture medium volume/well. The cultures were then re-incubated for a further $2 \mathrm{~h}$ $\left(37^{\circ} \mathrm{C}\right.$ and $\left.5 \% \mathrm{CO}_{2}\right)$ after which the cultures were removed from the incubator and the resultant formazan crystals were dissolved by adding an amount of MTT solubilization solution (10\% Triton $\mathrm{X}-100$ in acidic isopropanol; $0.1 \mathrm{M} \mathrm{HCl}$ ) equal to the original culture medium volume. Once the crystals were fully dissolved, the absorbance was measured at a wavelength of $570 \mathrm{~nm}$. Control media and healthy growing cell population were used as a reference. This cytotoxicity experiment was repeated $n=6$ times for each glass powder. 


\subsubsection{Live/deal cell viability assay}

Fluorescence-based live/dead assay (Molecular Probes Inc., Oregon, USA) was conducted using calcein AM (for labeling live cells) and Ethidium homodimer-1 (EthD-1, for labeling dead cells) to evaluate the viability of the bovine fibroblast cells after exposure to MTa glass powders. Details of both stains can be found in Appendix C: Live/Dead Cell Viability and Results. Adherent cells were first cultured with 1,3 , and $5 \mathrm{mg}$ of glass powders in 24 -well plates as confluent monolayers. The cells were then washed with PBS to remove serum esterase activity in growth media. Next, 1 $\mathrm{mL}$ of the combined live/dead assay reagents with standard concentrations ( $2 \mathrm{mM}$ calcein AM and $4 \mathrm{mM}$ EthD-1) were added directly to the wells to cover all cells. Then the cells were incubated for $30 \mathrm{~min}$ at room temperature. After incubation, wells were rinsed with PBS and labeled cells were viewed under microscope (ZOE Fluorescent Cell Imager, Bio-Rad Labs., California, USA).

\subsection{Statistical analysis}

Statistical analysis was carried out using Statistical Package for the Social Sciences (SPSS) software, version 24 (IBM Corp., New York, USA). Parametric, one-way ANOVA was used to compare the means of samples, followed by post-hoc analyses using independent t-tests. Random samples were tested using the Shapiro-Wilks test for normality, to ensure validity of using parametric analyses. Significance value of $\alpha=0.05$ was chosen. The number of samples varied and is mentioned in the respective method section of each test. 


\section{Results}

\subsection{Physical characterization}

Figure 4.1 shows the WAXRD patterns from the MBG samples. There are no significant peaks in the data, indicating that the samples are amorphous. The small peak seen in the 0 to $10^{\circ}$ region is further analyzed using SAXRD.

Figure 4.2 shows the SAXRD results for the MBG samples. All samples exhibited two diffraction peaks in the range from 0.2 to $2^{0}$ which are characteristic of the P6mm space group [77] in hexagonal crystal systems. The slight shift in the peaks are due to the changes in pore diameters and pore volumes between the samples.

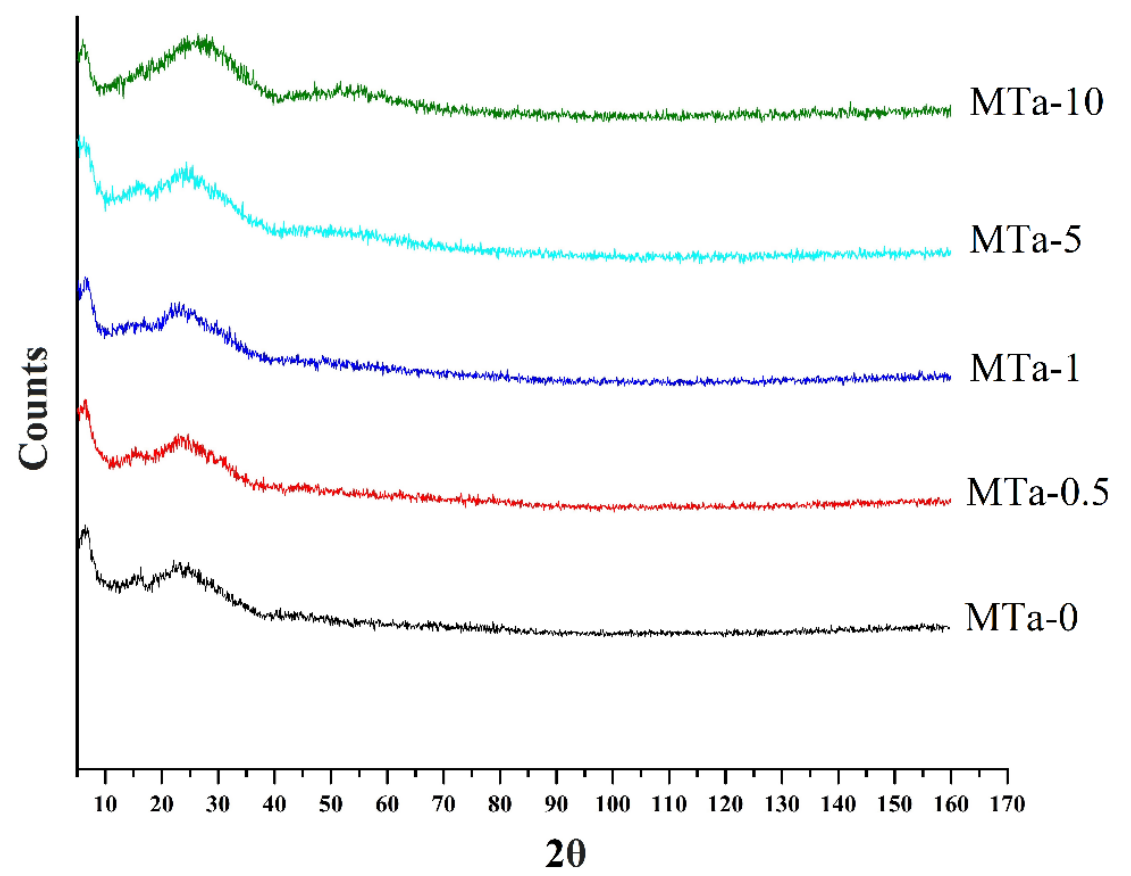

Figure 4.1: XRD results for MBG showing amorphous nature of all glasses. 


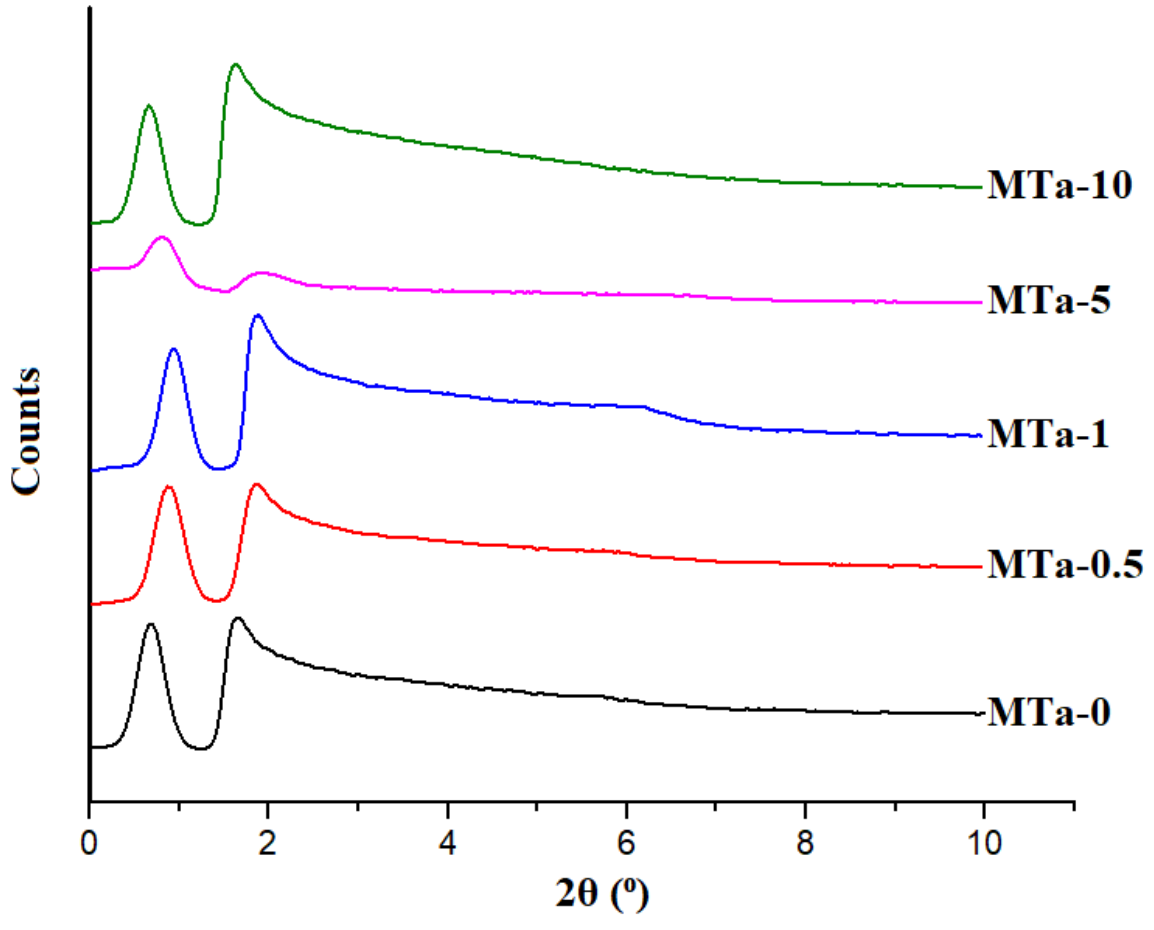

Figure 4.2: Small angle XRD results of MTa samples showing the two characteristic peaks of p6mm space groups in hexagonal systems.

TEM results are found in Figure 4.3 and show well-ordered, 2D hexagonal mesoporous channels in MBGs containing up to $0.5 \% \mathrm{Ta}$ (Figure 4.3a and b). However, MBGs with higher Ta content have disruptions in ordered channels (Figure 4.3c-e). It is difficult to quantify the number of disruptions, but surface area gives an idea of the relative magnitude. Table 4.1 shows the surface area (SA) and pore volumes (PV) of the corresponding samples. The SA decreases as the tantalum content and discontinuities, increase. Pore diameter and volume also decrease, with the exception of pore volume for MTa-5.

Table 4.1: BET surface area and, BJH pore volume and pore diameter of all samples.

\begin{tabular}{cccc}
\hline Sample & Surface Area $\left(\mathrm{m}^{2} / \mathbf{g}\right)$ & Pore Volume $\left(\mathrm{cm}^{3} / \mathbf{g}\right)$ & Pore Diameter $(\mathbf{n m})$ \\
\hline MTa- 0 & 373.87 & 0.27 & 4.3 \\
MTa- 0.5 & 373.98 & 0.22 & 4.2 \\
MTa- 1 & 353.14 & 0.21 & 4.1 \\
MTa- 5 & 328.44 & 0.23 & 4.0 \\
MTa- 10 & 297.55 & 0.17 & 3.9 \\
\hline
\end{tabular}



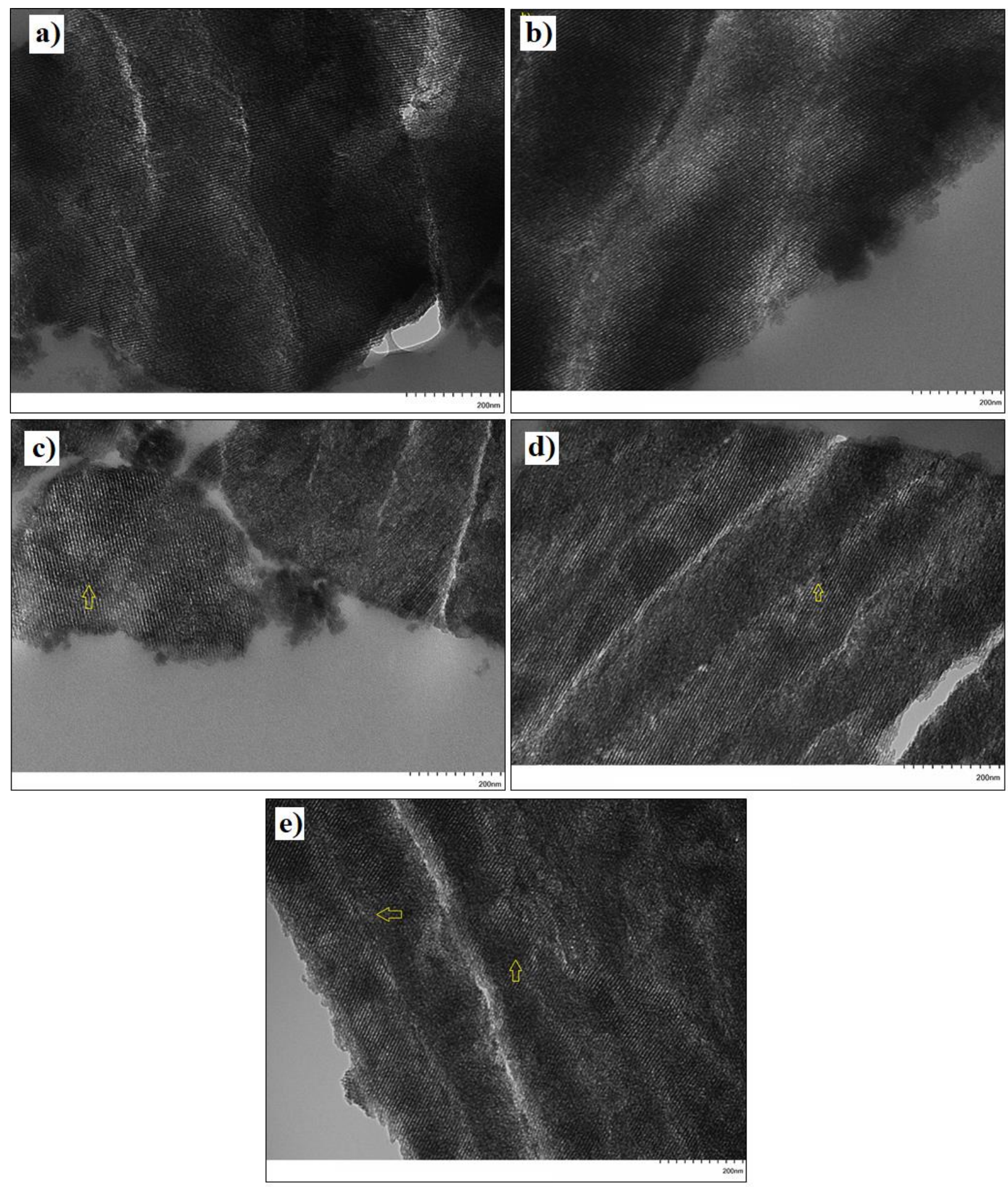

Figure 4.3: TEM images of a) MTa-0, b) MTa-0.5, c) MTa-1, d) MTa-5 and e) MTa-10 glasses. Arrow sign indicates discontinuity in the channel. The 2D hexagonal framework incurs more discontinuities as the Ta content increases. 


\subsection{Chemical characterization}

EDS results in Table 4.3 show the chemical composition of MBG samples. Results show increasing Ta content indicating proper incorporation of Ta in the samples. Specific EDS data (Table 4.3) are different from theoretical values (Table 4.2) due to the presence of extra oxygen from moisture in the atmosphere; the vacuum used while running EDS is insufficient to ensure the removal of all moisture from the samples. This causes an overall decrease in the wt.\% of the other elements present.

Table 4.2: Theoretical wt. \% of MBG compositions

\begin{tabular}{cccccc}
\hline Sample & $\boldsymbol{O}$ & $\boldsymbol{S i}$ & $\boldsymbol{C a}$ & $\boldsymbol{P}$ & $\boldsymbol{T a}$ \\
\hline MTa-0 & 50.3 & 35.3 & 9.5 & 4.9 & 0.0 \\
MTa-0.5 & 49.2 & 34.1 & 9.5 & 4.7 & 2.8 \\
MTa-1 & 48.2 & 32.9 & 8.9 & 4.6 & 5.4 \\
MTa-5 & 41.6 & 25.5 & 7.3 & 3.7 & 21.9 \\
MTa-10 & 36.2 & 19.3 & 5.9 & 3.0 & 35.6 \\
\hline
\end{tabular}

Table 4.3: Composition of MBG samples from EDS (wt. \%)

\begin{tabular}{cccccc}
\hline Sample & $\boldsymbol{O}$ & $\boldsymbol{S i}$ & $\boldsymbol{C a}$ & $\boldsymbol{P}$ & $\boldsymbol{T a}$ \\
\hline MTa- 0 & 58.6 & 31.4 & 7.2 & 2.8 & 0 \\
MTa- 0.5 & 55.5 & 31.2 & 8.0 & 2.5 & 2.8 \\
MTa- 1 & 58.2 & 27.9 & 6.7 & 2.1 & 5.1 \\
MTa- 5 & 47.6 & 23.6 & 6.0 & 1.8 & 21.0 \\
MTa- 10 & 37.7 & 20.2 & 5.3 & 1.2 & 35.6 \\
\hline
\end{tabular}

Wide scan XPS was conducted and atomic percentages (normalized without carbon) are shown in Table 4.4 for different MBG samples. The Ta $4 d$ peak was chosen for analysis since its peak has the least interference with other elements present and its intensity is high enough to get reliable data. 
Table 4.4: Normalized XPS data of MBG compositions (wt. \%)

\begin{tabular}{cccccc}
\hline Sample & $\boldsymbol{O}$ & $\boldsymbol{S i}$ & $\boldsymbol{C a}$ & $\boldsymbol{P}$ & $\boldsymbol{T a}$ \\
\hline MTa-0 & 45.9 & 45.7 & 5.2 & 3.1 & 0.0 \\
MTa-0.5 & 45.4 & 43.9 & 6.4 & 2.6 & 1.8 \\
MTa-1 & 44.0 & 41.7 & 6.3 & 2.6 & 5.4 \\
MTa-5 & 35.8 & 31.2 & 4.6 & 2.4 & 26.1 \\
MTa-10 & 27.1 & 21.9 & 3.9 & 0.9 & 46.2 \\
\hline
\end{tabular}

High resolution O1s spectra for three MBG samples are exhibited in Figure 4.4 with details of peak intensities in Table 4.5. The O1s peaks can be seen as a superposition of two individual peaks. These peaks come from the bridging oxygens (BO) and the non-bridging oxygens (NBO) found in the sample. It is observed that the overall O1s peak shifts to lower binding energy because of increasing number of NBOs. Since electron charge density is higher in NBO, it reduces the effective binding energy, relative to BO. For most samples, the amount of NBO is relatively the same until the $10 \%$ Ta incorporation.

Table 4.5: $B O$ and NBO binding energy, atomic percentage and shifting energy for $M B G$ samples

\begin{tabular}{c|cc|cc}
\hline \multirow{3}{*}{ Sample } & \multicolumn{2}{|c|}{ BO } & \multicolumn{2}{c}{ NBO } \\
\cline { 2 - 5 } & $\begin{array}{c}\text { Binding } \\
\text { energy }(\boldsymbol{e V})\end{array}$ & $\boldsymbol{a t . \%}$ & $\begin{array}{c}\text { Binding } \\
\text { energy }(\boldsymbol{e V})\end{array}$ & $\boldsymbol{a t . \%}$ \\
\hline MTa-0 & 530.98 & 96.46 & 528.88 & 3.54 \\
MTa-0.5 & 530.98 & 93.09 & 529.08 & 6.91 \\
MTa-1 & 530.88 & 94.95 & 528.88 & 5.05 \\
MTa-5 & 530.68 & 92.94 & 529.08 & 7.06 \\
MTa-10 & 530.58 & 84.85 & 529.08 & 18.15 \\
\hline
\end{tabular}

FTIR transmission spectra are shown in Figure 4.5 along with corresponding peaks. The peak at $440 \mathrm{~cm}^{-1}$ represents Si-O-Si bending vibrations [78], whereas the peak at $800 \mathrm{~cm}^{-1}$ indicates symmetric stretching of Si-O bond [79]. Characteristic peaks located at $1038 \mathrm{~cm}^{-1}$ and $1235 \mathrm{~cm}^{-1}$ are attributed to asymmetric stretching of Si-O bond [80]. Lastly, the peak observed at $934 \mathrm{~cm}^{-1}$ is identified as Si-NBO [81]. Across the series, increasing Ta content reduces the intensity of Si-O bending, symmetric and asymmetric stretching peaks. Conversely, increasing Ta concentration 
increases the intensity of the Si-NBO bonding peak. The increasing Si-NBO bonds are from Si-OSi being replaced by $\mathrm{Si}-\mathrm{O}-\mathrm{Ta}[82]$.
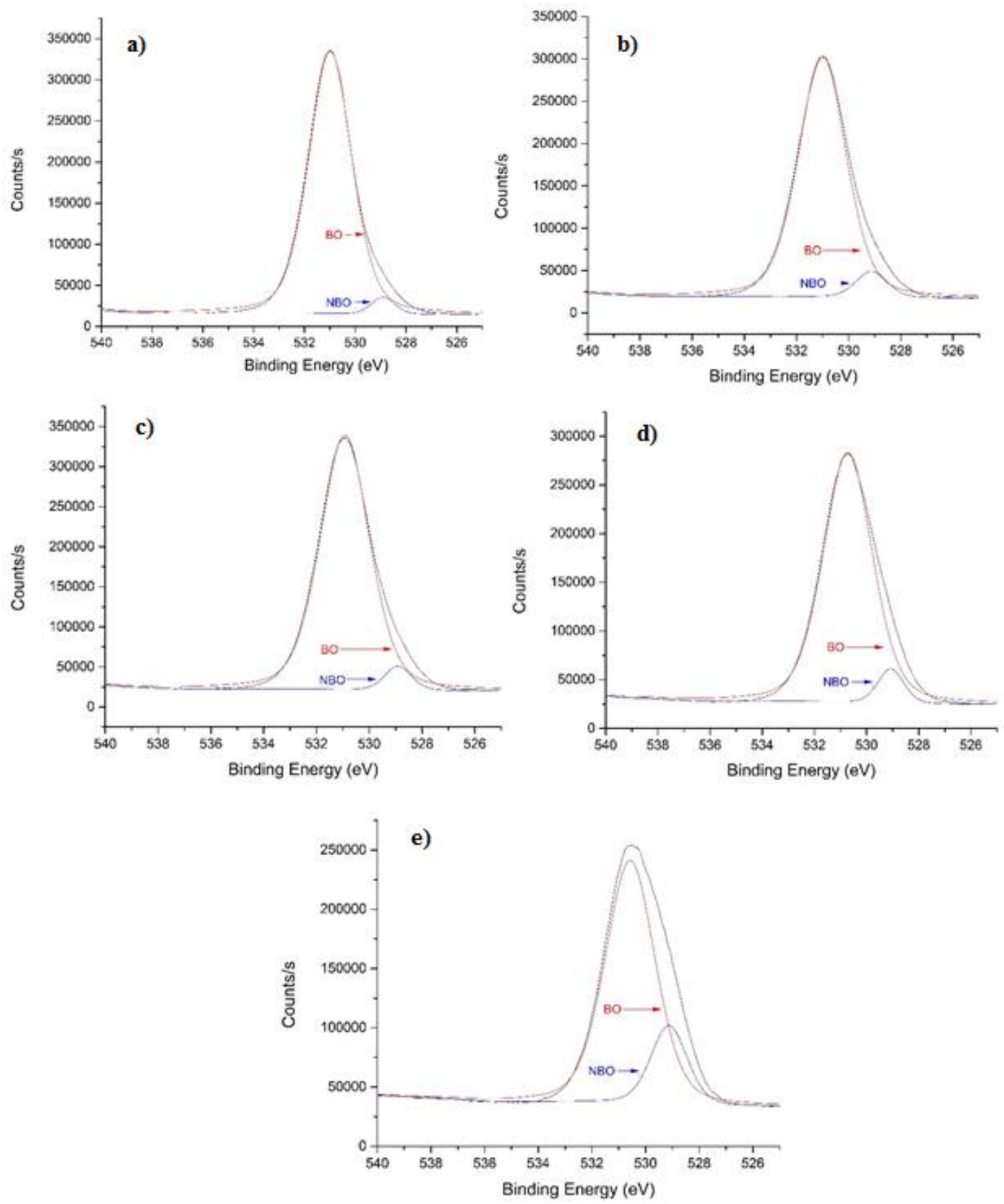

Figure 4.4: High resolution O1s spectrum for a) MTa-0, b) MTa-0.5, c) MTa-1, d) MTa-5 and e) MTa-10. The graphs show the BO peak, NBO peak and the combined peak. As Ta content is increased, the NBO content increases. 


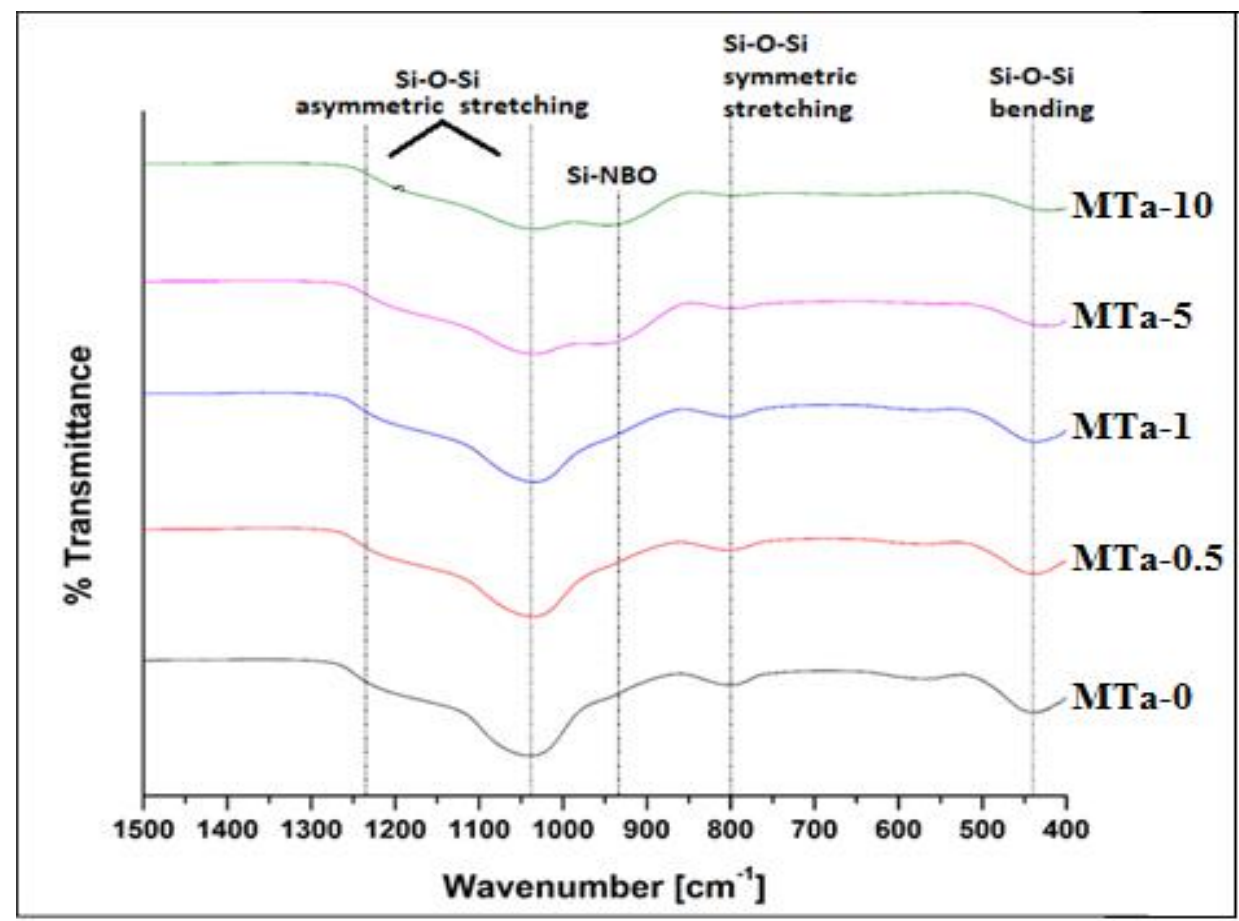

Figure 4.5: FTIR spectra of MTa samples with associated silicon bonds.

Zeta potential results are listed in Table 4.6. All MBGs show negative zeta potential because of the presence of negatively charged $\mathrm{Si}-\mathrm{O}$ groups on the glass surface. It is observed that zeta potential increased to $-20.4 \mathrm{mV}$ for MTa-0.5 glass but decreased below that of MTa- 0 for the remaining samples.

Table 4.6: Zeta potential of MBGs in water and polystyrene latex bead solution.

\begin{tabular}{cc}
\hline Sample & $\begin{array}{c}\text { Zeta potential } \\
(\boldsymbol{m} \boldsymbol{V})\end{array}$ \\
\hline MTa-0 & -22.7 \\
MTa-0.5 & -20.4 \\
MTa-1 & -24.8 \\
MTa-5 & -24.8 \\
MTa-10 & -31.1 \\
\hline
\end{tabular}




\subsection{In-vitro characterization}

\subsubsection{Ion release}

Ion release profiles for MBGs are plotted in Figure 4.6. Concentration of $\mathrm{Ca}, \mathrm{P}, \mathrm{Si}$ and Ta ions were measured 15, 30 and 60 mins after soaking in DI water. These time intervals were chosen based on the application of MBGs in hemostasis, as platelet plug formation in primary hemostasis occurs within the first hour [83]. There are two main trends that can be seen in the data. Firstly, the silicon ionic concentration decreases as tantalum increases. Secondly, ionic concentrations did not exhibit a significant difference from the 15 min mark to the 60 min mark for all the elements.

\subsubsection{Thromboelastography}

Table 4.7 shows $\mathrm{R}$ time (initiation of clot formation time) efficiency of all samples. Data from thromboelastographs for all samples are listed in Appendix B: Thromboelastography Results. R time efficacy is measured as the ratio of the mean $\mathrm{R}$ time of a sample in blood and mean $\mathrm{R}$ time of untreated blood. The result shows that Arista ${ }^{\circledR}$ is $91 \%$ more effective compared to no powder added in the TEG® cup. MTa-0 glass is $58 \%$ more effective while MTa-10 glass is $10 \%$ less effective compared to no treatment. However, the results for MTa-10 ranged from $-70 \%$ to $+210 \%$ of the mean, and so this result should be considered cautiously, as the mean may not accurately describe the data.

Table 4.7: $R$ time performance of different powder samples with respect to no powder added

\begin{tabular}{lc}
\hline Sample & Efficacy (\%) \\
\hline Arista® & $91 \%$ \\
MTa-0 & $58 \%$ \\
MTa-0.5 & $46 \%$ \\
MTa-1 & $26 \%$ \\
MTa-5 & $16 \%$ \\
MTa-10 & $-10 \%$ \\
\hline
\end{tabular}

The reason why the other parameters' (K, $\alpha_{T}$ and MA) values are not reported is due to the limitations in this method (discussed in the latter half of Appendix A: Thromboelastography). These limitations caused inconsistencies in the data for all the parameters; $\mathrm{K}$ time had missing values for different trials (i.e. the clot amplitude of some samples did not reach $20 \mathrm{~mm}$ to detect $\mathrm{K}$ 
time) and MA and $\alpha_{\mathrm{T}}$ values had very high variations in the data, sometimes over $100 \%$ standard deviation from the mean.

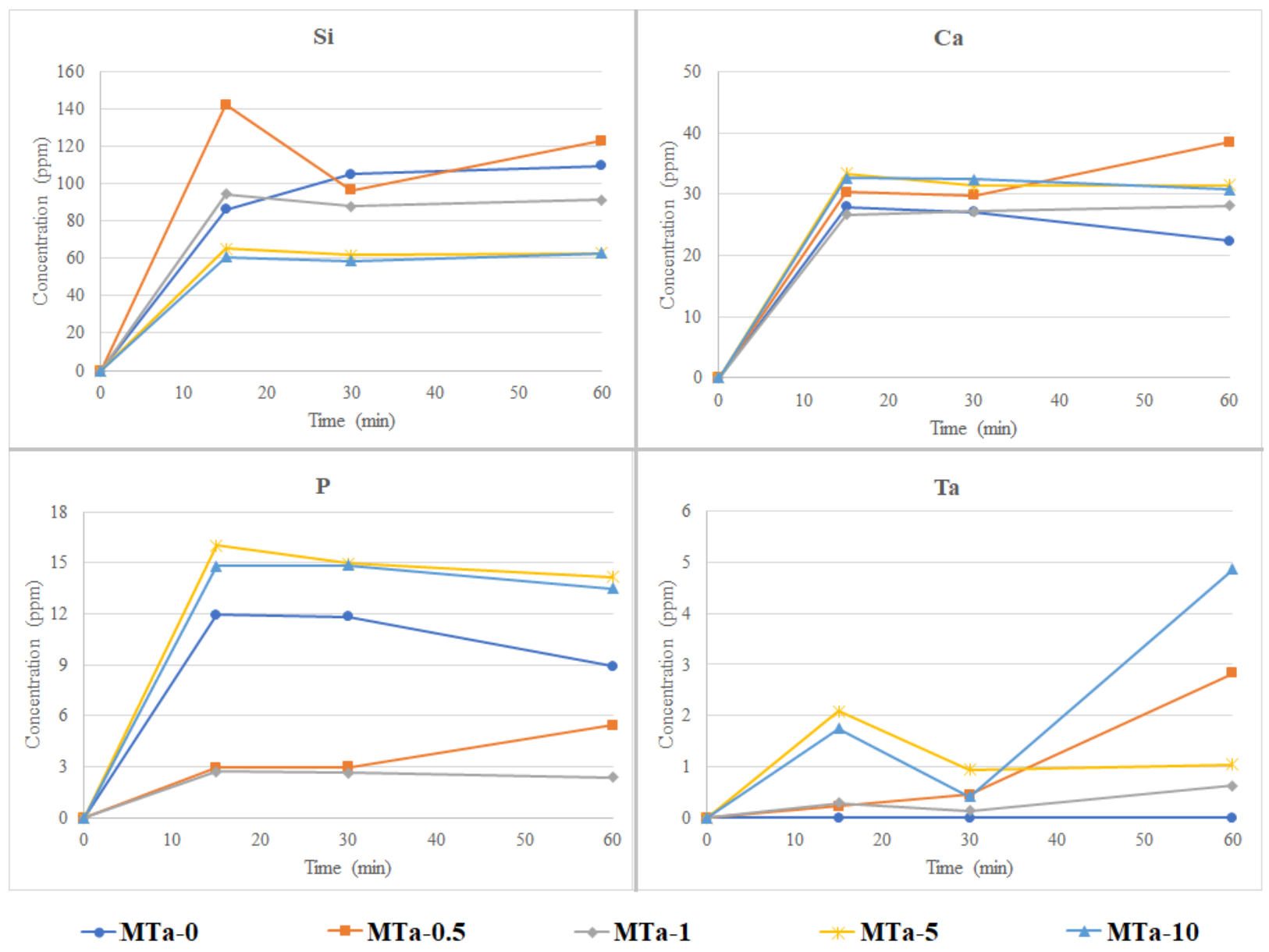

Figure 4.6: Ion release profiles from MBGs for silicon, calcium, phosphorous and tantalum.

\subsubsection{Hemostasis mouse model}

The tail bleeding time was used as a hemostasis model; results are shown in Figure 4.7. The plot shows a significant decrease in mean bleeding time of mice treated with Ta containing samples compared to the other controls (no treatment, Arista ${ }^{\circledR}$, and MBG without Ta). The statistical significance of these results was calculated and the $p$-values shown in Table 4.8. There is no significant different between no treatment, Arista ${ }^{\circledR}$ and the MTa-0 glass. However, there is a significant difference between all the Ta containing glasses and no treatment, Arista ${ }^{\circledR}$, and MTa0 . The only exception is between MTa- 1 and Arista ${ }^{\circledR}$ which has a $p$-value of 0.06 . 


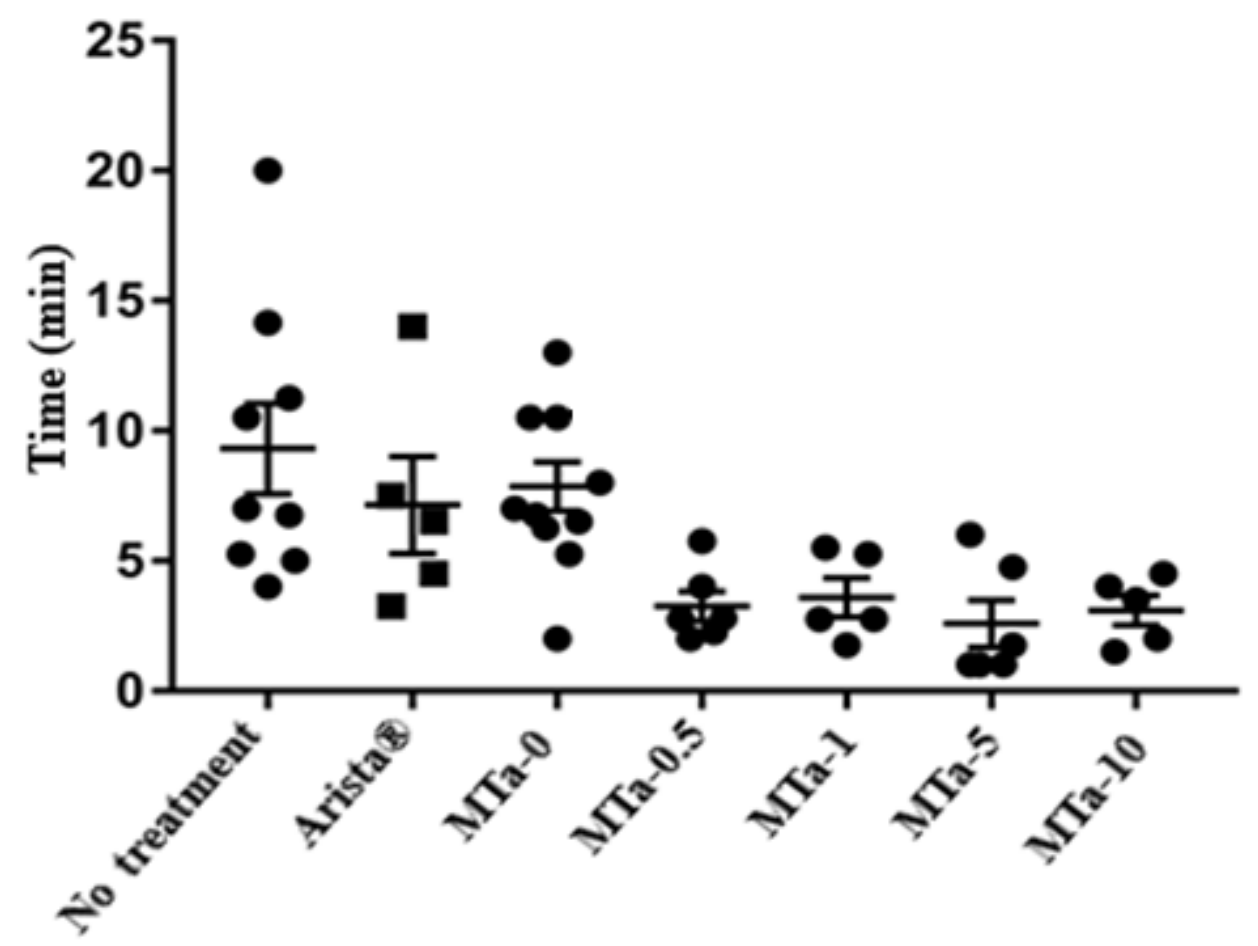

Figure 4.7: Tantalum containing bioactive glasses decreased the tail bleeding time in c57bl/6 mice. Results from hemostasis model are represented with individual symbols (•) representing one mouse; error bars represent standard error of the mean $(n=5-10)$. 
Table 4.8: Significance (p-values) between mean tail bleeding times from the hemostasis model.

\begin{tabular}{c|c|c|c|c|c|c|c}
\hline & $\begin{array}{c}\text { No } \\
\text { treatment }\end{array}$ & Arista ${ }^{\circledR}$ & MTa-0 & MTa-0.5 & MTa-1 & MTa-5 & MTa-10 \\
\hline $\begin{array}{c}\text { No } \\
\text { treatment }\end{array}$ & $x$ & 0.22 & 0.22 & 0.01 & 0.02 & 0.01 & 0.01 \\
\hline Arista ${ }^{\circledR}$ & & $x$ & 0.35 & 0.03 & 0.06 & 0.02 & 0.04 \\
\hline MTa-0 & & & $x$ & $<0.01$ & 0.01 & $<0.01$ & $<0.01$ \\
\hline MTa-0.5 & & & & $x$ & 0.36 & 0.27 & 0.43 \\
\hline MTa-1 & & & & & $x$ & 0.21 & 0.31 \\
\hline MTa-5 & & & & & & $x$ & 0.33 \\
\hline
\end{tabular}

\subsubsection{Hemolysis test}

The positive control (100\% lysed cells diluted to known concentrations) was used to create a fitting curve for correlating the absorbance values of the samples to the amount of hemolysis. The curve is found in Figure 4.8, with the fitting equation on the graph, and the correlated data found in Figure 4.9 multiplied by the dilution factor (20). Out of the five positive controls measured, only three fell within a linear range. The fourth was outside of the linear region, and the fifth was outside the measurement range of the machine. 


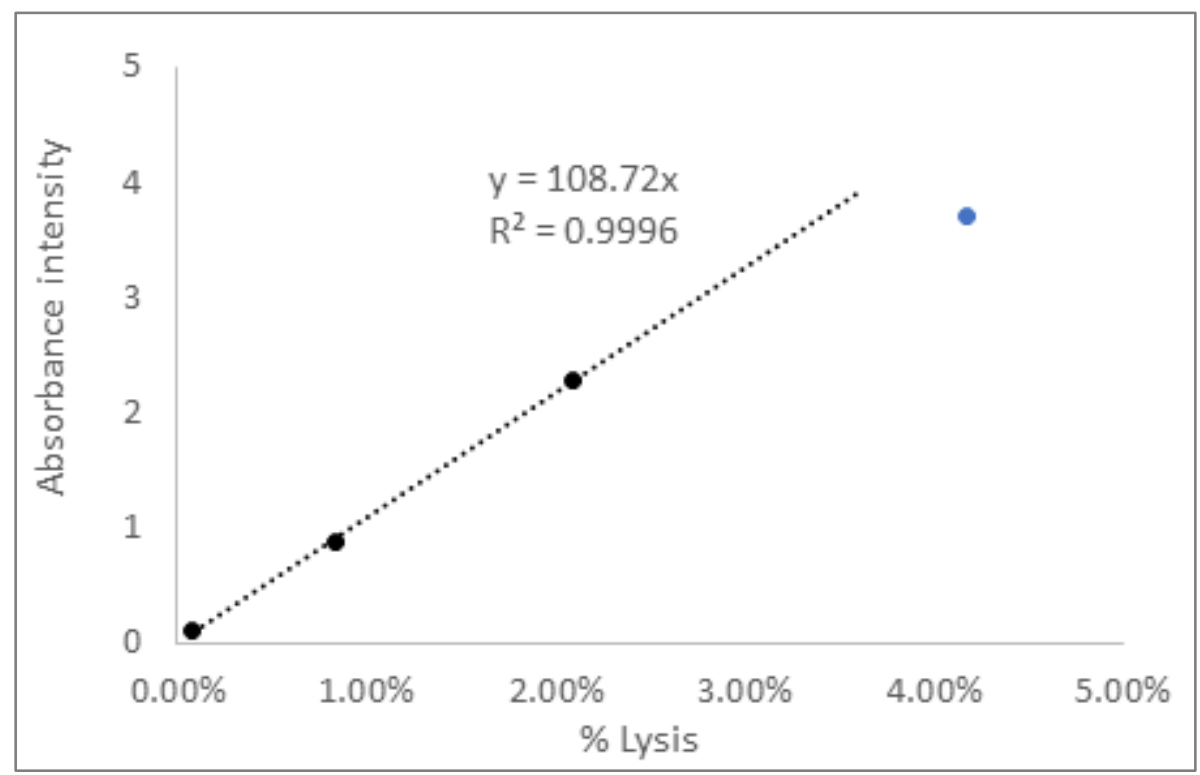

Figure 4.8: Fitting curve of the hemolysis test. Only three points fall into the linear range of the curve; the fourth point is omitted from the equation due to non-linearity and the fifth point is out of measurement range.

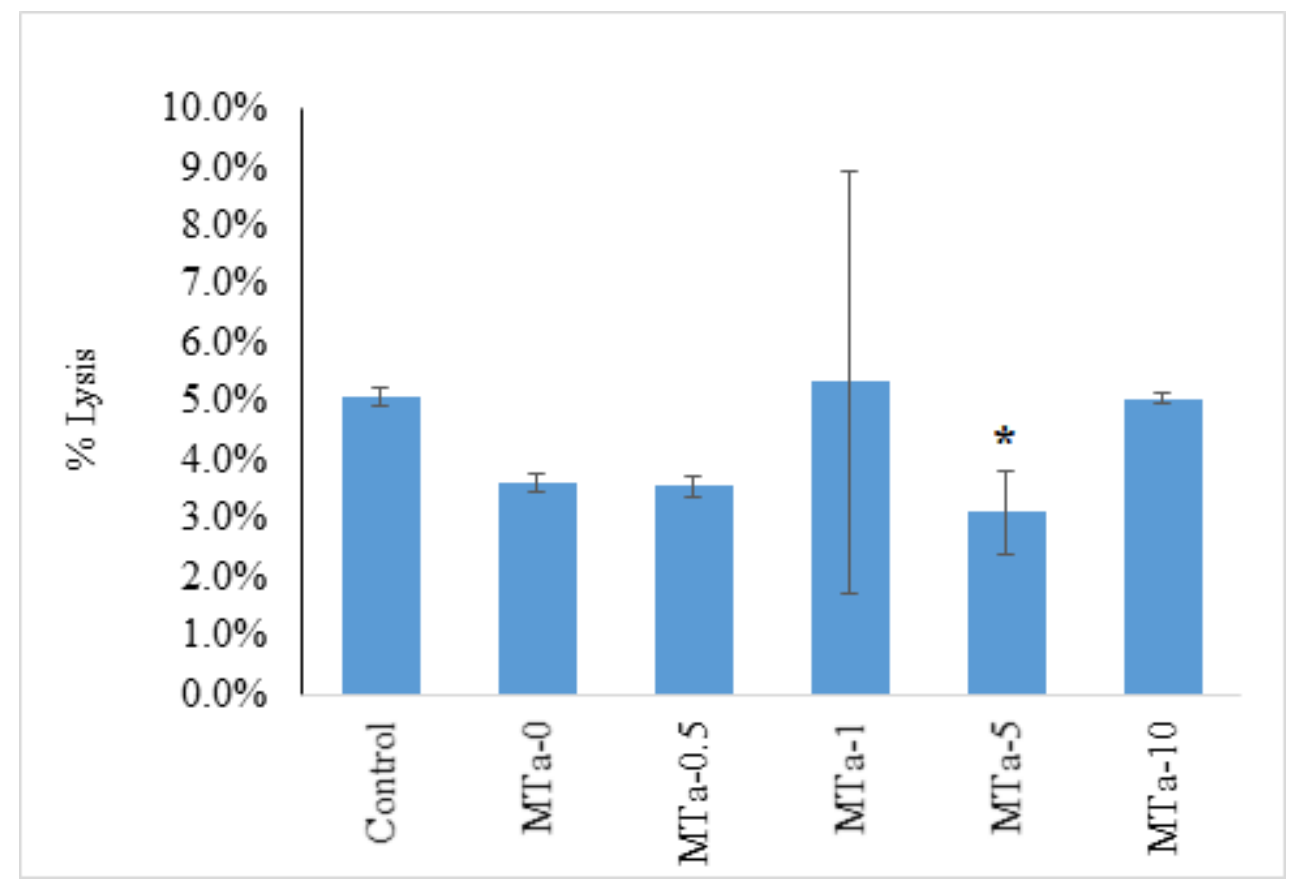

Figure 4.9: \% Lysis of each MTa sample and the negative control. Absorbance values were fitted to the equation in Figure 4.8, multiplied by the dilution factor (20) and graphed. Error bars represent standard deviations; * represents only $n=3$ samples $u$ sed. 
All the samples have no significant or significantly lower hemolysis \% compared to the control, meaning the MTa samples cause minimal hemolysis. The large standard deviation found in MTa1 is a result of some coagulation of the sample. MTa-1 and MTa-5 both had coagulation occur within the samples, causing the cells and plasma components to gel. This led to some RBCs being pipetted into the cuvette for two MTa-1 samples, as seen in Figure 4.10, artificially increasing the hemoglobin concentration and absorbance. To avoid this for subsequent samples, gelled samples were not tested; leading to the removal of two MTa-5 samples.

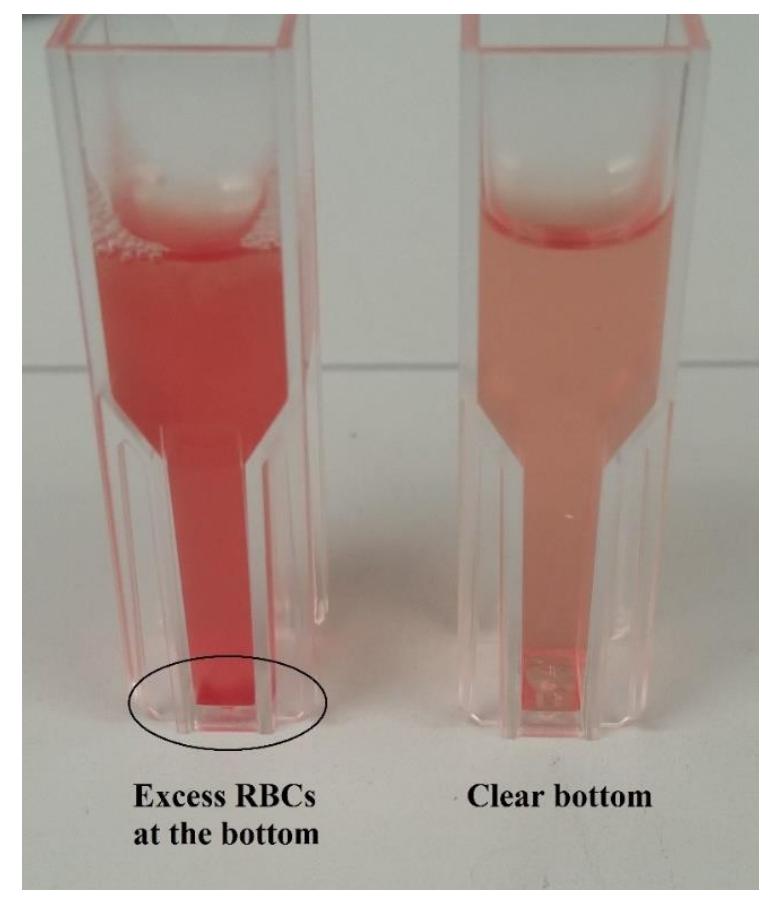

Figure 4.10: Comparison of MTa-1 (left) and MTa-O (right) samples. Some RBCs got into the MTa-1 samples because the blood clotted, and the plasma gelled with the cells.

Though not quantitatively measured, the coagulation of the blood during incubation is a key finding that will be discussed later in Section 5.

\subsection{Cytotoxicity}

To evaluate the relative cytotoxicity of the MBGs, cell viability tests were conducted. The results were normalized to the control group (cells grown without any MBG samples) and the results shown in Figure 4.11. From the results, it is seen that increasing Ta increases the number of live 
cells. The outlier is MTa- 5 which shows statistically the same viability as MTa- 0.5 and MTa- 0 at $1 \mathrm{mg}$ and $3 \mathrm{mg}$ doses, and MTa- 1 at $5 \mathrm{mg}$ dose which is statistically the same as MTa- 0 at $5 \mathrm{mg}$.

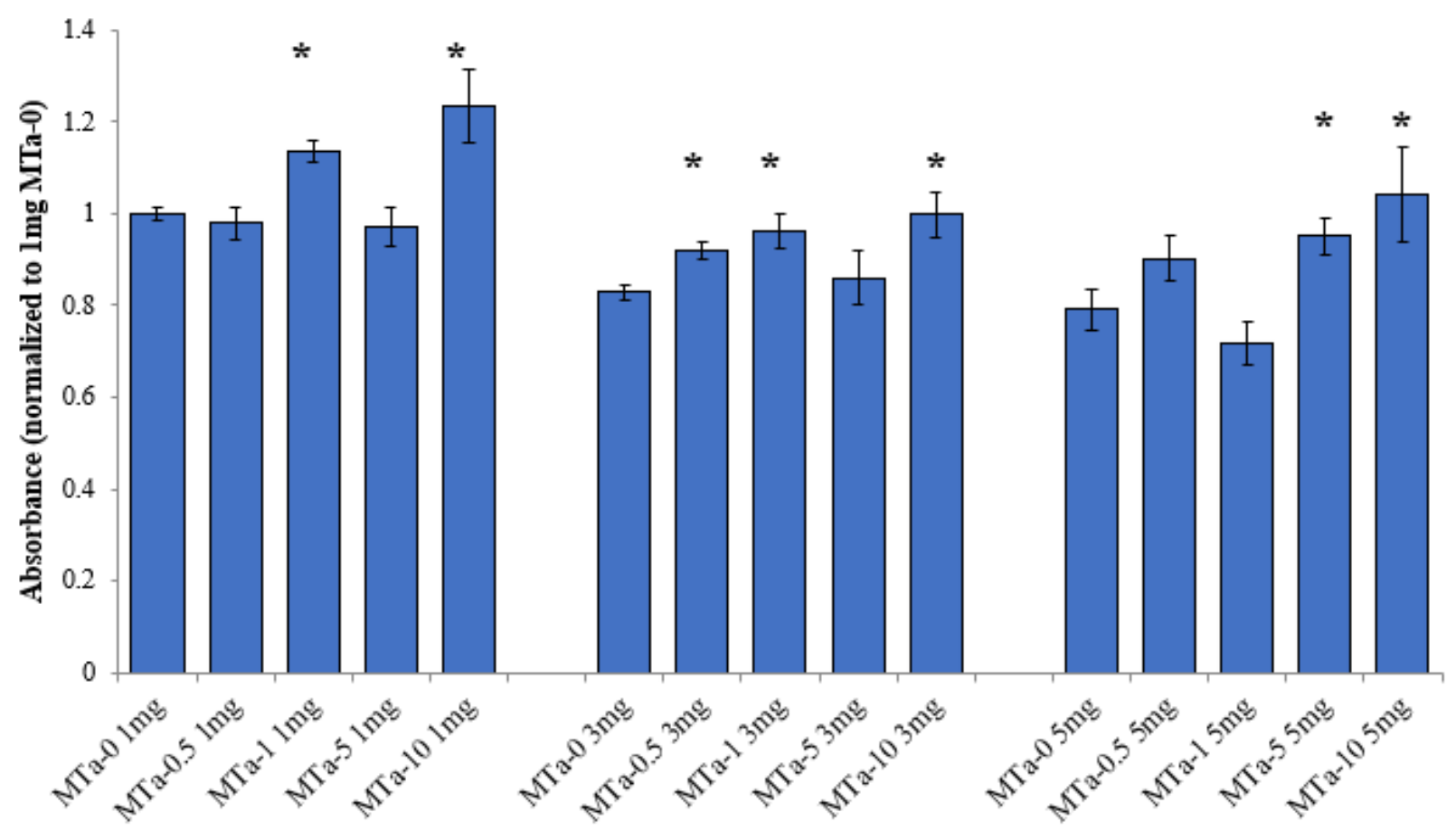

Figure 4.11: Cytotoxicity data of the MTa glasses normalized to control group without any sample. Glass composition and dose response was analyzed for each MTa sample. Increasing absorbance indicates more living cells. * indicates data is statistically different from MTa-O of same dose.

The other trend that is noticeable is that cell viability decreases with increasing MBG doses. This may be attributed to the higher number of ions released from the samples (as there is more sample) and the increased water absorption of the MBGs. As MBG content increases, more medium is sequestered into the porous network making fewer growth factors available for cell growth.

A sample of the live/dead assay results can be seen in Figure 4.12 with the complete results found in Appendix C: Live/Dead Cell Viability and Results. They confirm the findings from the MTT assay, showing more overall green cells as the amount of Ta is increased for individual doses. There are also more red (dead) and fewer green (live) cells as the dosage of powder increases from $1 \mathrm{mg}$ to $5 \mathrm{mg}$. The slight decrease in cell viability for $1 \mathrm{mg}$ of MTa-5 is not noticeable in these 
results. However, it should be noted that these results are qualitative, visual representations. Quantitative data is secured from the MTT assay.

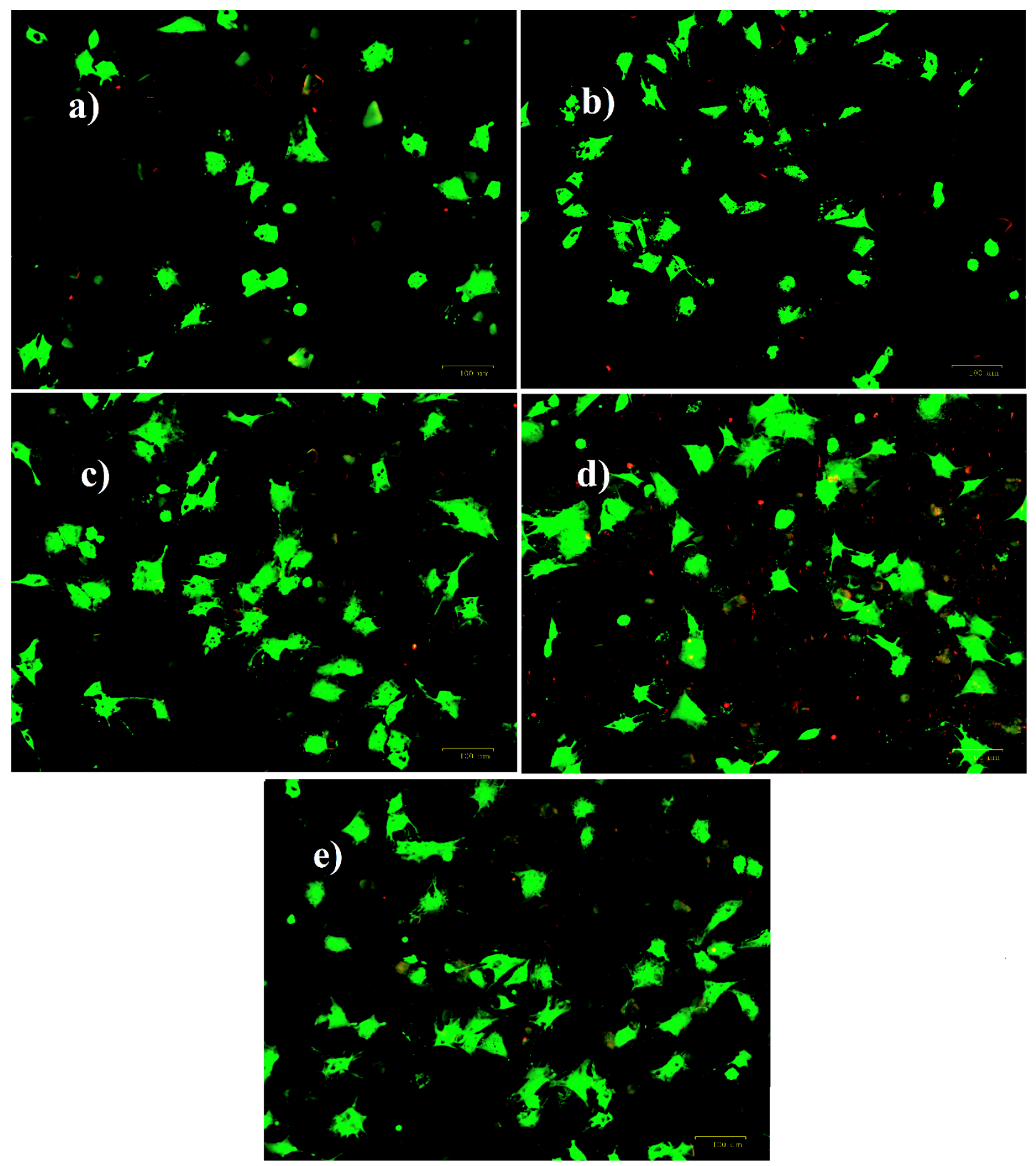

Figure 4.12: Live (green) and dead (red) assay images of a) MTa-0, b) MTa-0.5, c) MTa-1, d) MTa-5 and e) MTa-10, all at $1 \mathrm{mg}$ dose. Increasing Ta content shows increasing live cells. 


\section{Discussion}

Silica based MBGs have three features which make them ideal for hemostasis: high surface area, negative surface charge and highly tunable modifier composition. $\mathrm{Ca}^{2+}$ ions are relied on for speeding up hemostasis as they are a key element in the coagulation cascade. However, this research also looks at the possibility of Ta playing a role in enhancing hemostatic activity. In order to be certain that these three features were present, complete physical and chemical characterization of the MBGs was required. WAXRD showed amorphicity of the glasses (no crystal peaks in Figure 4.1) while the SAXRD shows peaks found from the repeating nanostructure of the p6mm space group of hexagonal lattice systems (Figure 4.2). These nanostructures are the mesoporous channels of the MBGs and are visually confirmed using TEM. There is a slight right shift of the SAXRD peaks, caused from a decrease in pore diameter, as seen in MTa-0 to MTa-1 in Figure 4.3; this pore diameter decrease is confirmed by the BJH data. However, MTa-5 and MTa-10 have a slight left shift of their peaks (Figure 4.2). This may be due to the discontinuities in the channel structure, observed in TEM, and the broken channels appearing as larger channels when diffracting the $\mathrm{x}$-rays. The decrease in pore diameter is likely due to the Ta addition to the glass. Ta has a coefficient of thermal expansion (CTE) of $6.7 \times 10^{-6} \mathrm{~K}^{-1}$ [84], which is more than double that of the other MBG materials (without Ta). Using estimate models of CTE from Bellucci et al., with Hall coefficient [85], it is calculated that the CTE for MTa-0 is $3.08 \times 10^{-6} \mathrm{~K}^{-1}$. The Hall coefficients were chosen based on the conclusions of Bellucci and the fact that the coefficients were determined at high temperatures (comparable to the calcination temperatures used in this work). Due to the CTE of Ta being so large, it would have a greater change in volume relative to the surrounding structure. As the temperature was reduced after calcination, volumetric shrinkage would be greater with more Ta in the sample, thereby causing the pore diameter to decrease. The mismatch in CTE also means that some stress is built up within the Ta samples during cooling. These can cause nanoscale defects in the structure as the Ta content in increased. With bulk bioactive glasses, these nanoscale defects are sufficient to significantly increase the ion solubility of the glasses in aqueous medium [73]. Therefore, in MBGs, where the channels are just an order

of magnitude greater than the defect size, the effect of nanoscale defects is more prominent and causes breaks in the channel structure. This explains the discontinuities seen in the TEM images (Figure 4.3), and the nitrogen adsorption results (Table 4.1). Volumetric shrinking of the samples with more Ta causes pore diameter (and consequently pore volume) to decrease, which then 
reduces overall surface area. Further reduction in surface area could result from blocking of the channels due to the defects in the MBGs.

Chemical characterization of the MBGs show discrepancies in the individual results for EDS (Table 4.3) and XPS (Table 4.4) that make the compositions look vastly different. Besides the oxygen content, EDS showed greater incorporation of calcium than was shown in the XPS data. The reason for this is that XPS measures surface composition and penetrates only a few nanometers into the sample. It has been shown that calcium concentrations are higher in the bulk compared to the surface [86] and as a result XPS would not reflect that accurately. Due to Ta having a much higher molecular weight compared to calcium, a small molar increase of Ta representation on the surface leads to a much higher wt. \%. Therefore, Ta content in the XPS results (Table 4.4) is 5$10 \%$ higher than the theoretical values in Table 4.2. Deconvolution of the XPS oxygen peak gives information about the bridging and non-bridging oxygens found in the sample. The trend was an increase in the number of NBOs with increasing Ta content. This was also observed in the FTIR data (Figure 4.5) where the intensity of the Si-NBO peak increased in line with Ta content. This data is supported by the fact that higher number of discontinuities/defects would leave more edges with $\mathrm{Si}^{-} \mathrm{O}^{-}$or $\mathrm{Ta}^{-} \mathrm{O}^{-}$.

Ion release analysis did not indicate any notable trends with Ta incorporation in the MBGs. There is a decrease in the amount of Si released (with increasing Ta content) but that is expected due to the decreasing Si content in the glasses. A likely explanation for lack of other trends is that the time interval chosen (based on relevance to hemostat application) was too short for high ion release; steady state does not appear to have been achieved, considering ion release. However, it was confirmed that the elements present in the samples ( $\mathrm{Si}, \mathrm{Ca}, \mathrm{P}$ and $\mathrm{Ta}$ ) eluted into solution, as seen in Figure 4.6, and so corresponding therapeutic effects of the ions would be possible.

With confirmation of the physical and chemical properties of the MBGs, in-vitro testing was conducted. There are two ways in which a high surface area accelerates coagulation. The first method is by sequestering water from the blood and concentrating the clotting factors [64]. Concentration speeds up the kinetics of the coagulation cascade by localizing all the coagulation factors/co-factors, leading to faster fibrin formation. All synthesized MBGs have a high surface area and pore volume and so can absorb water quickly. Even MTa-10 with the greatest amount of 
discontinuities in its channel structure still has SA of nearly $300 \mathrm{~m}^{2} / \mathrm{g}$. Arista ${ }^{\circledR}$ works on a similar principle but instead of having a porous network, the starch-based particles swell to incorporate the water [87]. While this allows for greater clot initiation, as seen by the R time efficacy in the TEG data, it does not guarantee better clot strength or full clot formation. The other method by which high SA benefits hemostasis is through providing many reaction sites for the blood clotting factors. Hemostasis is a surface mediated process [63], [88], [89]. The initial cascade from the intrinsic pathway relies on the activation of factor XI by thrombin in the presence of a negatively charged surface. With a high amount of surface sites available in MBGs, the conversion of factor XI to XIa can occur on multiple places instead of just on the collagen of the injury site. The high number of surface sites are also negatively charged, required for factor XI activation. All MTa samples have a high negative charge in an aqueous environment, as measured by zeta potential. This negative charge develops from the cation exchange of the MBGs into the medium, followed by silanol formation, and then condensation of the surface silanol groups leaving $\mathrm{Si}^{-} \mathrm{O}^{-}$. These are the same initial reactions followed for HCA formation mentioned in Section 1.1. Higher Ta content results in a larger number of Si-NBO bonds forming (as confirmed by FTIR and XPS), and so the surface negativity also increased with increasing Ta content. A $10 \mathrm{~mol} \%$ addition of Ta to the silica MBG decreased zeta potential from $-22 \mathrm{mV}$ to $-30 \mathrm{mV}$. There is a slight positive shift in zeta potential between MTa- 0 and MTa-0.5. This could be from addition of a small amount of Ta into the glass structure, and Ta's role as a network former in small quantities $(<1 \mathrm{~mol} \%)$ in bioactive glasses [72].

Tuning the modifier composition in MBGs can drastically change their effects. In glasses, Ca in any quantity acts as a modifier for the glass network. This means it speeds up the degradation of the glass. It is known that calcium ions play a key role in the coagulation cascade. They are a major factor for activation of prothrombin (factor II) into thrombin (the key factor for converting fibrinogen into fibrin). They are also a cofactor in the activation of factors V, VII, VIII, IX, X, and XIII [30] as they are bound to other factors or molecules. Therefore, having excess $\mathrm{Ca}^{2+}$ near the damaged site would increase the speed at which the coagulation cascade can proceed. As MBGs are absorbing water from the blood, they are undergoing cation exchange and so consistently provide the surrounding media with $\mathrm{Ca}^{2+}$. This is likely the reason why coagulation occurred in the hemolysis tests even with the presence of the anticoagulant. EDTA is known strong chelator of $\mathrm{Ca}^{2+}$ and is added in a quantity to blood to occupy all the $\mathrm{Ca}$, and disallow its participation in 
the coagulation cascade [90]. Since the blood still coagulated, it can be postulated that the MTa samples released sufficient $\mathrm{Ca}^{2+}$ to allow coagulation to occur.

This research determined whether Ta incorporation into silica based MBGs can affect hemostasis and to what degree. Reviewing the physical properties, Ta caused a decrease in the SA and PV, indicating that there may be a compromised hemostatic effect. However, there are more NBOs (so faster theoretical degradation) and greater negative surface charge with increasing Ta; and these would be expected to accelerate hemostasis. It was assumed that the SA may play a greater role in hemostasis than chemical composition, since Arista ${ }^{\circledR}$ uses similar mechanisms for hemostasis and it shows clinically significant results. TEG data also supported this assumption but only regarding the clot initiation time. Other TEG clot data (e.g. clot strength, rate of clot formation, etc.) was inconsistent and unreliable for adequate comparison. However, the tail-cut model and cytotoxicity tests show that there was a pronounced positive effect with respect to hemostasis of Ta in MBGs. Bleeding times from the hemostasis model demonstrate that, compared to controls (no treatment, MBG with no Ta, or the commercial hemostat Arista $\left.{ }^{\circledR}\right)$, all Ta-containing MBGs stopped bleeding significantly sooner. Cytotoxicity was slightly decreased as Ta content increased, regardless of dosage. This suggests that the hypothesis considering Ta accelerating the coagulation process is correct; it effects coagulation either directly (through chemical reactions with the coagulation factors) or indirectly (affecting the environment of the cells). Further in-vitro investigations will be required to better characterize this effect and confirm the findings. 


\section{Conclusions}

- Ta containing MBGs can be synthesized by the sol-gel route to contain up to $10 \mathrm{~mol} \% \mathrm{Ta}$ without crystallization.

- Increasing Ta content above $\sim 1 \mathrm{~mol} \%$ will reduce SA, PV and pore diameter while causing some breaks in the nanostructure of MBGs. However, there is increased number of NBOs which is correlated to increased bioactivity.

- The number of ions released from Ta-MBGs does not vary significantly within short durations (between 15 to $60 \mathrm{~min}$ ). However, there appears to be sufficient $\mathrm{Ca}^{2+}$ released to positively effect coagulation, as seen by the hemolysis tests.

- Ta containing MBGs perform significantly better at achieving hemostasis with an in-vivo mouse model, than Arista ${ }^{\circledR}$ and MBG without Ta.

- MBGs are non-hemolytic.

- $\quad$ Increasing Ta in MBGs increases cell viability. 


\section{Recommendations for future work}

More in-vitro and in-vivo tests need to be conducted in order to determine how Ta affects hemostasis.

a) Ex-vivo clotting assays such as Prothrombin Time and Activated Partial Thromboplastin Time (PT and APTT) should be done. This will determine whether the intrinsic or extrinsic pathway is more activated.

b) Blood clotting assays can be performed with Ta-MBGs and anticoagulant (heparin, citrate, etc.) treated blood to see whether clotting can be initiated in patients under anticoagulant therapy or those with coagulopathies.

c) In-vivo animal liver or arterial injury models should be tested to see whether Ta-MBGs are suitable in cases of heavier bleeding.

d) Ca can be removed from the MBGs to determine whether Ta can activate the factors in place of $\mathrm{Ca}$.

e) Antibacterial elements such as copper, zinc or silver can be added to the Ta-MBGs to determine whether their release imparts an antibacterial nature to the MBGs.

f) Cytotoxicity can be tested at multiple time frames to see the effect over time. 


\section{Appendix A: Thromboelastography}

Thromboelastography (TEG) is a technique for measuring the viscoelastic properties of blood. The machine contains torsion wire attached to a pin, suspended inside a cup containing the blood sample. The cup is rotated $4^{\circ} 45^{\prime}$, six times a minute, back and forth to simulate the behavior of venous blood. As the blood in the cup begins to coagulate, it sticks to the pin and causes it to rotate with the cup. This rotation is transduced into an electrical signal through the torsion wire [91]. The graph obtained is plotted as clot size in millimeters, $\mathrm{mm}$, over time in minutes, min. Five main parameters are obtained from the graph of the TEG results:

- $\quad \mathrm{R}=$ initial clot formation time ( $\mathrm{min})$

- $\mathrm{K}=$ time taken for the clot to reach $20 \mathrm{~mm}(\mathrm{~min})$

- $\alpha_{\mathrm{T}}=$ rate of clot formation from $\mathrm{R}$ to $\mathrm{K}(\mathrm{mm} / \mathrm{min})$

- $\quad \mathrm{MA}=$ the maximum clot size $(\mathrm{mm})$ also referred to as the maximum clot strength

\section{Limitations of Thromboelastography}

There are sources of error while conducting TEG that creates limitations on the reproducibility of data. The human errors occur during blood collection and sample preparation. While operating and extracting mouse blood, there were times when clots occurred on the syringe needle. These clots were removed before starting the TEG machine, but this meant removing platelets from the blood. This would affect all the parameters measured by the machine. Another human error would be in the time taken from introducing samples (MTa or Arista ${ }^{\circledR}$ ) to starting the machine. Dur to $\mathrm{R}$ time being a few seconds for some samples, a difference of 2 seconds could be a significant variation in the data.

A large procedural error that occurs is regarding the blood samples used. There was a lot of variation in the mice regarding gender, age, and body composition (fat \%) of mice, all of which affect the results [92]. This also made it difficult to get enough blood (at least $680 \mu \mathrm{L}$ ) from each mouse to run the tests sometimes. 


\section{Appendix B: Thromboelastography Results}

Numerical data from TEG graphs. Some values of K time are missing because clots did not reach $20 \mathrm{~mm}$ in size. In these cases, the $\alpha$ values are from the R time to the time taken to reach MA (instead of K time).

\section{R time}

\begin{tabular}{|c|c|c|c|c|c|c|c|}
\hline Sample & & & $(\min$ & & & Mean & STD. \\
\hline Arista $®$ & 0.2 & 0.1 & 0.2 & 0.2 & 0.2 & 0.2 & 0.04 \\
\hline nothing & 1.5 & 1.9 & 1.8 & 4.1 & 2.2 & 2.3 & 1.04 \\
\hline MTa-0 & 0.4 & 0.3 & 0.9 & 1.8 & 1.3 & 0.9 & 0.63 \\
\hline nothing & 1.2 & 1.5 & 2.4 & 3.2 & 2 & 2.1 & 0.79 \\
\hline$M T a-0.5$ & 0.6 & 1.8 & 0.8 & 1.2 & 1.5 & 1.2 & 0.49 \\
\hline nothing & 2.2 & 2 & 3.3 & 2.3 & 2 & 2.4 & 0.54 \\
\hline MTa-1 & 2.7 & 2 & 0.2 & 0.8 & 1.3 & 1.4 & 0.98 \\
\hline nothing & 3 & 2.3 & 0.8 & 1.3 & 1.2 & 1.7 & 0.90 \\
\hline MTa-5 & 0.6 & 1.5 & 0.9 & 0.8 & 1.2 & 1.0 & 0.35 \\
\hline nothing & 1.3 & 1.8 & 1.1 & 2.2 & 0.7 & 1.4 & 0.59 \\
\hline MTa-10 & 1.6 & 0.8 & 3.5 & 1.2 & 1 & 1.6 & 1.09 \\
\hline nothing & 1.9 & 1.7 & 1.6 & 1.6 & 0.8 & 1.5 & 0.42 \\
\hline
\end{tabular}

\section{K time}

\begin{tabular}{c|ccccc}
\hline Sample & \multicolumn{5}{|c}{ K (min) } \\
\hline Arista ${ }^{\circledR}$ & 2 & 0.8 & 1.2 & 1.6 & 1.1 \\
nothing & - & 19.1 & 2.1 & - & 12.8 \\
MTa-0 & 8.2 & 16.2 & - & 1.8 & 3.6 \\
nothing & 13.2 & 8.6 & - & 5.7 & 3.8 \\
MTa-0.5 & 4.8 & - & - & 2.1 & 3.3 \\
nothing & 6.2 & - & - & 4.6 & 3 \\
MTa-1 & 2.4 & - & 8.5 & 2.8 & 2.3 \\
nothing & 3.6 & 16.6 & 14.7 & 2.9 & 1.5 \\
MTa-5 & 2.7 & 9.9 & 6.4 & - & 5.7 \\
nothing & 3.8 & 8.8 & 1.8 & - & 4.2 \\
MTa-10 & 4.8 & - & 26.1 & 2.4 & 5.8 \\
nothing & 9.4 & 18.8 & 18.5 & 2.2 & 5.3 \\
\hline
\end{tabular}


$\boldsymbol{\alpha}$

\begin{tabular}{|c|c|c|c|c|c|c|c|}
\hline Sample & & & $\alpha\left({ }^{\circ}\right)$ & & & Mean & STD. \\
\hline Arista $\AA$ & 76.8 & 82.9 & 77 & 78.1 & 78.8 & 78.72 & 2.48 \\
\hline nothing & 24 & 30.3 & 65.7 & 8.5 & 30.6 & 31.82 & 20.96 \\
\hline MTa-0 & 43.4 & 39.8 & 28.3 & 62.7 & 46.8 & 44.2 & 12.47 \\
\hline nothing & 43.7 & 41.6 & 20 & 40 & 52.9 & 39.64 & 12.06 \\
\hline MTa-0.5 & 43.2 & 15 & 33.9 & 58.5 & 48.7 & 39.86 & 16.51 \\
\hline nothing & 36 & 28.6 & 13 & 46.3 & 57.4 & 36.26 & 16.94 \\
\hline MTa-1 & 58.7 & 14.9 & 58 & 59.6 & 58.7 & 50.0 & 19.62 \\
\hline nothing & 52.2 & 25.1 & 45.5 & 57.8 & 70.3 & 50.18 & 16.72 \\
\hline MTa-5 & 60.1 & 30.3 & 38.3 & 41.2 & 38.5 & 41.68 & 11.07 \\
\hline nothing & 59.5 & 46.3 & 72.6 & 20.3 & 52.3 & 50.2 & 19.38 \\
\hline MTa-10 & 49.2 & 33.2 & 13 & 61 & 39.1 & 39.1 & 18.01 \\
\hline nothing & 40.9 & 30.6 & 37 & 64.5 & 42.6 & 43.12 & 12.81 \\
\hline
\end{tabular}

MA

\begin{tabular}{c|ccccc|c|c}
\hline Sample & \multicolumn{5}{|c|}{ MA(mm) } & Mean & STD. \\
\hline Arista ${ }^{\circledR}$ & 22.9 & 37.1 & 53.8 & 30.5 & 39.6 & 36.8 & 11.51 \\
nothing & 5.7 & 21.9 & 57.8 & 7.3 & 27.2 & 23.98 & 21.04 \\
MTa-0 & 28.6 & 21.1 & 14.1 & 52.6 & 46.6 & 32.6 & 16.48 \\
nothing & 23.5 & 26.1 & 15.1 & 47.1 & 50.6 & 32.48 & 15.54 \\
MTa-0.5 & 45.5 & 16.7 & 9.9 & 41.5 & 43.4 & 31.4 & 16.76 \\
nothing & 45.1 & 19.5 & 11.5 & 46.2 & 50.6 & 34.58 & 17.77 \\
MTa-1 & 48.9 & 16.8 & 27 & 47.1 & 52.4 & 38.44 & 15.64 \\
nothing & 51 & 23.1 & 25.3 & 53.6 & 58 & 42.2 & 16.64 \\
MTa-5 & 52.2 & 26.4 & 40.2 & 16.9 & 41.4 & 35.42 & 13.83 \\
nothing & 49.8 & 28 & 52.8 & 9.6 & 44 & 36.84 & 17.99 \\
MTa-10 & 42.8 & 19.2 & 22 & 45.2 & 43.6 & 34.56 & 12.81 \\
nothing & 35 & 23.7 & 21.5 & 56.9 & 43.8 & 36.18 & 14.66 \\
\hline
\end{tabular}




\section{Appendix C: Live/Dead Cell Viability and Results}

Bovine fibroblasts used in the cell experiments were isolated from the central ligament of the metacarpal-carpal joint of 12-18 month old calves. Harvested ligaments were cleaned of extraneous fat and cut into $<1 \mathrm{~mm}^{3}$ pieces, and then digested in DMEM culture media containing $0.25 \%$ collagenase A (Roche Diagnostics Corporation) for 36 hours at $37^{\circ} \mathrm{C}$. Viable cells were seeded in culture flasks and maintained in DMEM medium containing 10\% FBS and antibiotics (100U/mL penicillin, $100 \mathrm{mg} / \mathrm{mL}$ streptomycin). Cell cultures were grown in an incubator maintained at $37^{\circ} \mathrm{C}$ and $95 \%$ relative humidity supplemented with $5 \% \mathrm{CO}_{2}$. Cells were cultured up to passage 5 for the experiments with media changes every 2-3 days.

Two dyes have been employed to measure the amount of live and dead cells. The live cells were measured using the calcein acetoxymethyl (calcein AM) dye. This dye is lipid soluble and therefore permeates through cell membranes. Within the cell, it reacts with esterases to release calcein - a fluorescent molecule. Any esterases are washed out of the medium beforehand and so the only calcein generated is from within the living cells.

Ethidium homodimer-1 (EthD-1) is a membrane-impermeable fluorescent dye that binds to DNA. Intact cells do not uptake any EthD-1. However, cells that are lysed have their membranes broken and so the dye can permeate and bind to the DNA, indicating the number of dead cells. The following images are superimposed results of the live (green) and dead (red) staining. The images have been post-processed with enhanced exposure and contrast to get a better look at the cells. 


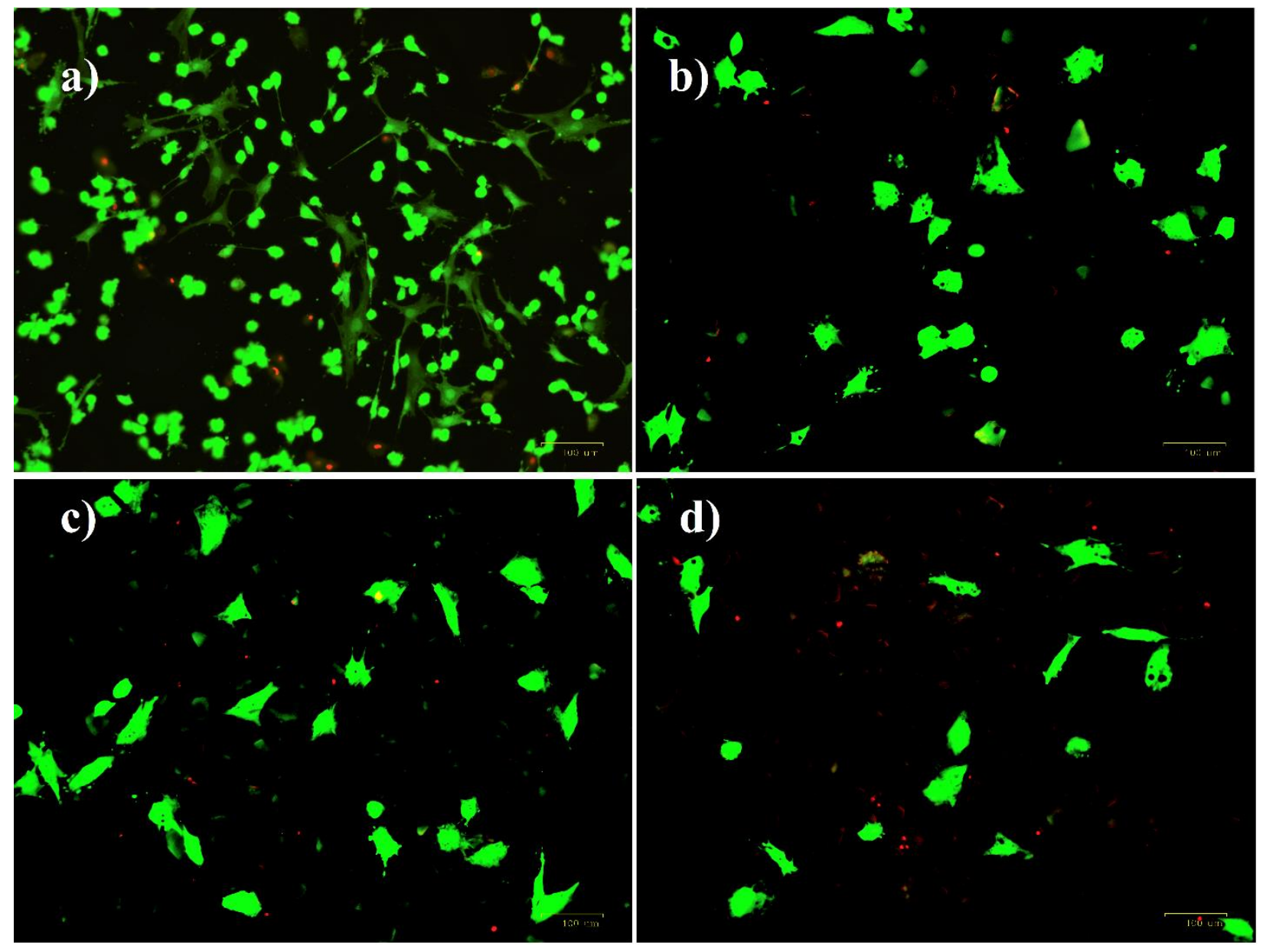

Figure A.0.1: Live (green) and dead (red) images of bovine fibroblast cells after culturing with a) nothing (control), b) $1 \mathrm{mg} \mathrm{MTa-0,} \mathrm{c)} 3 \mathrm{mg} \mathrm{MTa-0,} \mathrm{and} \mathrm{d)} 5 \mathrm{mg} M T a-0$. 


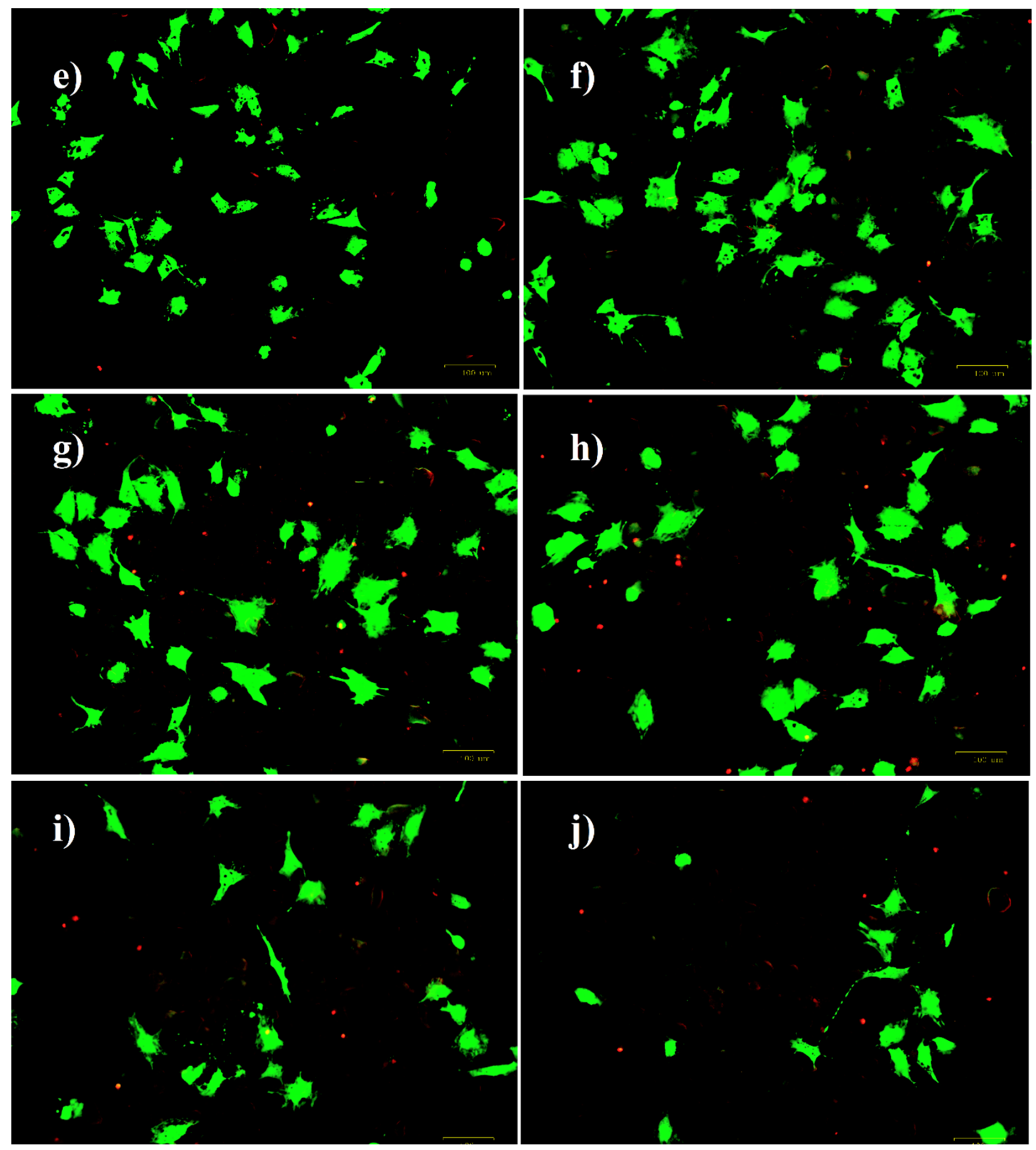

Figure A.0.2: Live (green) and dead (red) images of bovine fibroblast cells after culturing with e) $1 \mathrm{mg}$ MTa-0.5, f) $1 \mathrm{mg} M T a-1$, g) $3 \mathrm{mg} M T a-0.5$, h) $3 \mathrm{mg} M T a-1$, i) $5 \mathrm{mg}$ MTa-0.5, and j) $5 \mathrm{mg}$ MTa-1. 


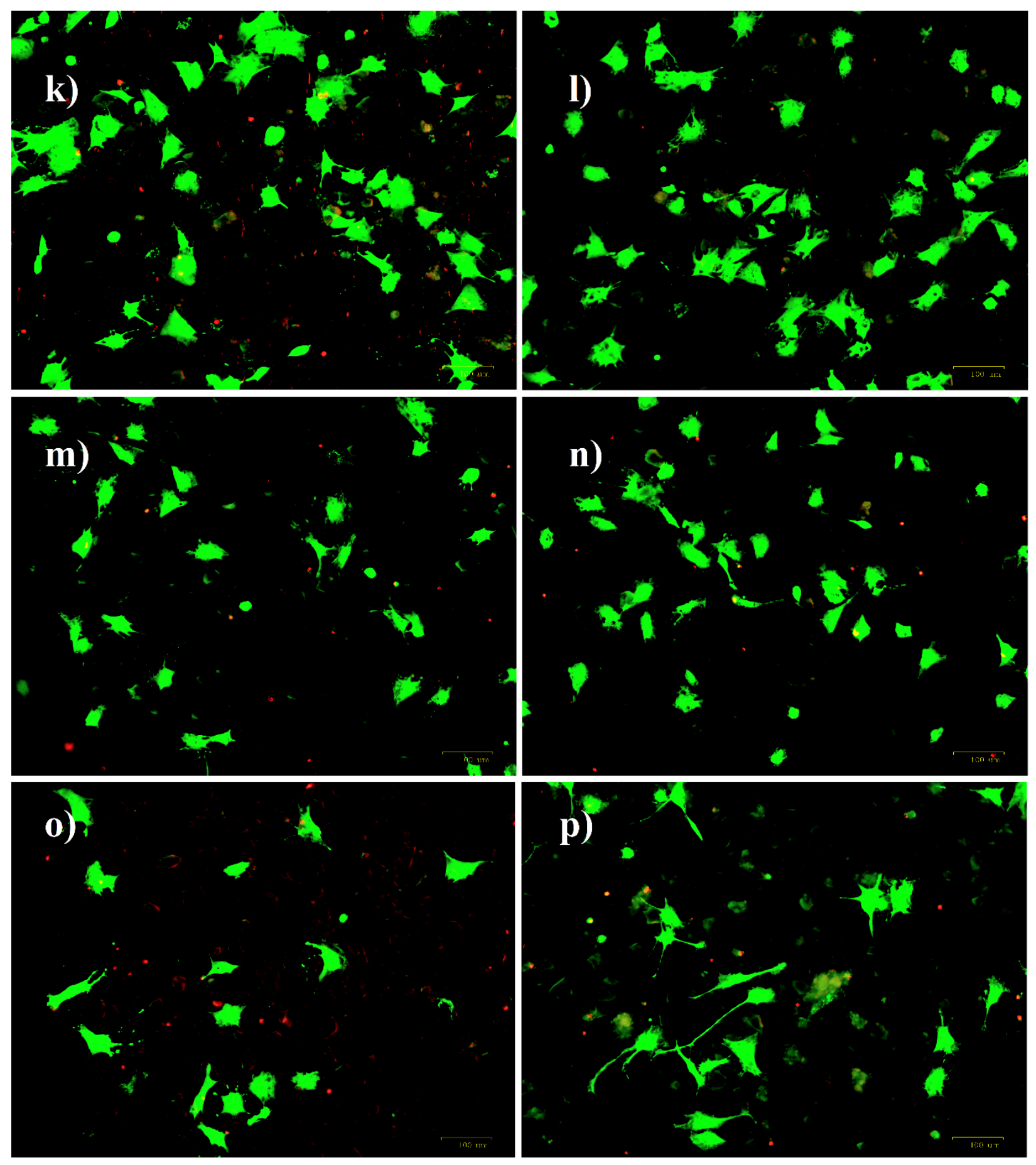

Figure A.0.3: Live (green) and dead (red) images of bovine fibroblast cells after culturing with k) $1 \mathrm{mg}$ MTa-5, l) $1 \mathrm{mg}$ MTa-10, m) $3 \mathrm{mg}$ MTa-5, n) 3 mg MTa-10, o) 5 mg MTa-5, and p) 5 mg MTa-10. 


\section{References}

[1] "glass | Definition, Composition, \& Facts," Encyclopedia Britannica. [Online]. Available: https://www.britannica.com/technology/glass. [Accessed: 17-Oct-2018].

[2] J. R. Jones, "Review of bioactive glass: From Hench to hybrids," Acta Biomater., vol. 9, no. 1, pp. 4457-4486, Jan. 2013.

[3] M. Z. David Levy, The Sol-Gel Handbook, 1st ed., vol. 1-3. Wiley-VCH Verlag GmbH \& Co. KGaA, Boschstr., 2015.

[4] L. L. Hench, R. J. Splinter, W. C. Allen, and T. K. Greenlee, "Bonding mechanisms at the interface of ceramic prosthetic materials," J. Biomed. Mater. Res., vol. 5, no. 6, pp. 117-141, Nov. 1971.

[5] L. L. Hench, “Third-Generation Biomedical Materials," Science, vol. 295, no. 5557, pp. 1014-1017, Feb. 2002.

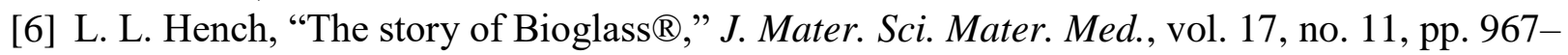
978, Nov. 2006.

[7] W. C. A. Vrouwenvelder, C. G. Groat, and K. de Groot, "Better histology and biochemistry for osteoblasts cultured on titanium- doped bioactive glass: Bioglass $45 \%$ compared with iron-, titanium-, fluorine- and boron-containing - bioactive glasses," vol. 15, no. 2, p. 10, 1994.

[8] U. M. Gross and V. Strunz, "The anchoring of glass ceramics of different solubility in the femur of the rat," J. Biomed. Mater. Res., vol. 14, no. 5, pp. 607-618, Sep. 1980.

[9] C. Wu et al., "Copper-containing mesoporous bioactive glass scaffolds with multifunctional properties of angiogenesis capacity, osteostimulation and antibacterial activity,"

Biomaterials, vol. 34, no. 2, pp. 422-433, Jan. 2013.

[10] Laboratoire de Physiopathologie Orale et Moléculaire, Centre de Recherche des Cordeliers, INSERM, UMRS 872, Equipe 5, 15-21 rue de l'Ecole de Médecine, F-75270 Paris Cedex 06, France et al., "Effects of strontium-doped bioactive glass on the differentiation of cultured osteogenic cells," Eur. Cell. Mater., vol. 21, pp. 130-143, Feb. 2011.

[11] A. Ito, K. Ojima, H. Naito, N. Ichinose, and T. Tateishi, "Preparation, solubility, and cytocompatibility of zinc-releasing calcium phosphate ceramics," J. Biomed. Mater. Res., vol. 50, no. 2, pp. 178-183, May 2000.

[12] M. Vallet-Regí, C. V. Ragel, and A. J. Salinas, "Glasses with Medical Applications," Eur. J. Inorg. Chem., vol. 2003, no. 6, pp. 1029-1042, Mar. 2003.

[13] P. Sepulveda, J. R. Jones, and L. L. Hench, "Characterization of melt-derived 45S5 and sol-gel-derived 58S bioactive glasses," J. Biomed. Mater. Res., vol. 58, no. 6, pp. 734-740, 2001.

[14] V. Meynen, P. Cool, and E. F. Vansant, "Verified syntheses of mesoporous materials," Microporous Mesoporous Mater., vol. 125, no. 3, pp. 170-223, Oct. 2009.

[15] M. Hartmann, "Ordered Mesoporous Materials for Bioadsorption and Biocatalysis," Chem. Mater., vol. 17, no. 18, pp. 4577-4593, Sep. 2005.

[16] M. Vallet-Regí, "Ordered Mesoporous Materials in the Context of Drug Delivery Systems and Bone Tissue Engineering," Chem. - Eur. J., vol. 12, no. 23, pp. 5934-5943, Aug. 2006.

[17] S. Pourshahrestani et al., "Gallium-containing mesoporous bioactive glass with potent hemostatic activity and antibacterial efficacy," J. Mater. Chem. B, vol. 4, no. 1, pp. 71-86, Dec. 2015. 
[18] T. Peltola et al., "Calcium phosphate formation on porous sol-gel-derived $\mathrm{SiO} 2$ and $\mathrm{CaO}-$ P2O5-SiO2 substratesin vitro," J. Biomed. Mater. Res., vol. 44, no. 1, pp. 12-21, Jan. 1999.

[19] I. Izquierdo-Barba, A. J. Salinas, and M. Vallet-Regí, "Bioactive Glasses: From Macro to Nano," Int. J. Appl. Glass Sci., vol. 4, no. 2, pp. 149-161, Jun. 2013.

[20] X. Yan, C. Yu, X. Zhou, J. Tang, and D. Zhao, "Highly Ordered Mesoporous Bioactive Glasses with Superior In Vitro Bone-Forming Bioactivities," Angew. Chem. Int. Ed., vol. 43, no. 44, pp. 5980-5984, Nov. 2004.

[21] L. Sherwood and C. Ward, Human physiology: from cells to systems, 3rd ed. 2016.

[22] F. Martini et al., Fundamentals of anatomy \& physiology. 2018.

[23] P. F. Fogarty, M. D. Tarantino, A. Brainsky, J. Signorovitch, and K. M. Grotzinger, "Selective validation of the WHO Bleeding Scale in patients with chronic immune thrombocytopenia," Curr. Med. Res. Opin., vol. 28, no. 1, pp. 79-87, Jan. 2012.

[24] G. Gutierrez, H. D. Reines, and M. E. Wulf-Gutierrez, "Clinical review: Hemorrhagic shock," Crit. Care, vol. 8, no. 5, pp. 373-381, 2004.

[25] L. Copley, "Bleeding time, other in vivo hemostasis tests and the arrest of hemorrhage," p. 23.

[26] W. D. Spotnitz and S. Burks, "State-of-the-Art Review: Hemostats, Sealants, and Adhesives II: Update As Well As How and When to Use the Components of the Surgical Toolbox," Clin. Appl. Thromb., vol. 16, no. 5, pp. 497-514, Oct. 2010.

[27] A. Waugh, A. Grant, J. S. Ross, and K. J. W. Wilson, Ross and Wilson anatomy and physiology in health and illness, 9th ed., repr. Edinburgh: Churchill Livingstone, 2001.

[28] P. Atluri, The Surgical Review: An Integrated Basic and Clinical Science Study Guide. Lippincott Williams \& Wilkins, 2006.

[29] Z. Ruggeri, "Structure and Function of von Willebrand Factor," Thromb. Haemost., vol. 82, no. 08, pp. 576-584, 1999.

[30] "The coagulation cascade: initiation, maintenance, and regulation - Biochemistry (ACS Publications).”[Online]. Available:

https://pubs.acs.org/doi/abs/10.1021/bi00107a001?journalCode=bichaw. [Accessed: 31-Aug2018].

[31] T. Loof, C. Deicke, and E. Medina, The role of coagulation/fibrinolysis during

Streptococcus pyogenes infection, vol. 4. 2014.

[32] "Ten Leading Causes of Death and Injury - PDFs|Injury Center|CDC," 24-Jul-2018. [Online]. Available: https://www.cdc.gov/injury/wisqars/LeadingCauses.html. [Accessed: 20-Aug-2018].

[33] H. Khoshmohabat, S. Paydar, H. M. Kazemi, and B. Dalfardi, "Overview of Agents Used for Emergency Hemostasis," Trauma Mon., vol. 21, no. 1, p. e26023, Feb. 2016.

[34] C. N. Sambasivan, S. D. Cho, K. A. Zink, J. A. Differding, and M. A. Schreiber, "A highly porous silica and chitosan-based hemostatic dressing is superior in controlling hemorrhage in a severe groin injury model in swine," Am. J. Surg., vol. 197, no. 5, pp. 576580, May 2009.

[35] H. R. Champion, R. F. Bellamy, C. P. Roberts, and A. Leppaniemi, "A Profile of Combat Injury," J. Trauma Acute Care Surg., vol. 54, no. 5, p. S13, May 2003.

[36] Committee on Military Trauma Care's Learning Health System and Its Translation to the Civilian Sector, Board on Health Sciences Policy, Board on the Health of Select Populations, Health and Medicine Division, and National Academies of Sciences, Engineering, and Medicine, A National Trauma Care System: Integrating Military and Civilian Trauma 
Systems to Achieve Zero Preventable Deaths After Injury. Washington, D.C.: National Academies Press, 2016.

[37] K. Irita, "Risk and crisis management in intraoperative hemorrhage: Human factors in hemorrhagic critical events," Korean J. Anesthesiol., vol. 60, no. 3, p. 151, 2011.

[38] D. S. Kauvar and C. E. Wade, "The epidemiology and modern management of traumatic hemorrhage: US and international perspectives," vol. 9, p. 9, 2005.

[39] S. Pourshahrestani, E. Zeimaran, I. Djordjevic, N. A. Kadri, and M. R. Towler, "Inorganic hemostats: The state-of-the-art and recent advances," Mater. Sci. Eng. C, vol. 58, pp. 1255-1268, 2016.

[40] B. Kheirabadi, "Evaluation of topical hemostatic agents for combat wound treatment," US Army Med. Dep. J., pp. 25-37, Jun. 2011.

[41] T. Maesen, "Chapter 1 - The Zeolite Scene - An Overview," in Studies in Surface Science and Catalysis, vol. 168, J. Čejka, H. van Bekkum, A. Corma, and F. Schüth, Eds. Elsevier, 2007, pp. 1-12.

[42] F. Arnaud et al., "Exothermic Reaction in Zeolite Hemostatic Dressings: QuikClot ACS and ACS+®," Ann. Biomed. Eng., vol. 36, no. 10, pp. 1708-1713, Oct. 2008.

[43] L. B. Williams and S. E. Haydel, "Evaluation of the medicinal use of clay minerals as antibacterial agents,” Int. Geol. Rev., vol. 52, no. 7-8, pp. 745-770, May 2010.

[44] L. F. Littlejohn, J. J. Devlin, S. S. Kircher, R. Lueken, M. R. Melia, and A. S. Johnson, "Comparison of Celox-A, ChitoFlex, WoundStat, and Combat Gauze Hemostatic Agents Versus Standard Gauze Dressing in Control of Hemorrhage in a Swine Model of Penetrating Trauma: Hemostatic Agents Vs. Standard Gauze For Hemorrhage Control In Swine," Acad. Emerg. Med., vol. 18, no. 4, pp. 340-350, Apr. 2011.

[45] B. S. Kheirabadi et al., "Safety Evaluation of New Hemostatic Agents, Smectite Granules, and Kaolin-Coated Gauze in a Vascular Injury Wound Model in Swine:," J. Trauma Inj. Infect. Crit. Care, vol. 68, no. 2, pp. 269-278, Feb. 2010.

[46] A. C. Offodile, B. Chen, A. S. Aherrera, and L. Guo, "Microporous Polysaccharide Hemospheres Potentiate Ischemia-Induced Skin Flap Necrosis in a Murine Model:," Plast. Reconstr. Surg., vol. 139, no. 1, pp. 59e-66e, Jan. 2017.

[47] H. T. Spencer, J. T. Hsu, D. R. McDonald, and L. I. Karlin, "Intraoperative anaphylaxis to gelatin in topical hemostatic agents during anterior spinal fusion: a case report," Spine J. Off. J. North Am. Spine Soc., vol. 12, no. 8, pp. e1-6, Aug. 2012.

[48] A. H. Smith, C. Laird, K. Porter, and M. Bloch, "Haemostatic dressings in prehospital care," Emerg. Med. J., vol. 30, no. 10, pp. 784-789, Oct. 2013.

[49] D. S. Warren, S. P. H. Sutherland, J. Y. Kao, G. R. Weal, and S. M. Mackay, "The Preparation and Simple Analysis of a Clay Nanoparticle Composite Hydrogel," J. Chem. Educ., vol. 94, no. 11, pp. 1772-1779, Nov. 2017.

[50] Y. Murakami, M. Yokoyama, H. Nishida, Y. Tomizawa, and H. Kurosawa, "In vivo and in vitro evaluation of gelation and hemostatic properties of a novel tissue-adhesive hydrogel containing a cross-linkable polymeric micelle," J. Biomed. Mater. Res. B Appl. Biomater., vol. 91B, no. 1, pp. 102-108, Oct. 2009.

[51] Z. Mirzakhanian, K. Faghihi, A. Barati, and H. R. Momeni, "Synthesis of superabsorbent hydrogel nanocomposites for use as hemostatic agent," Int. J. Polym. Mater. Polym.

Biomater., vol. 65, no. 15, pp. 779-788, Oct. 2016. 
[52] N. Annabi, S. M. Mithieux, P. Zorlutuna, G. Camci-Unal, A. S. Weiss, and A. Khademhosseini, "Engineered cell-laden human protein-based elastomer," Biomaterials, vol. 34, no. 22, pp. 5496-5505, Jul. 2013.

[53] N. Annabi et al., "Engineering a highly elastic human protein-based sealant for surgical applications," Sci. Transl. Med., vol. 9, no. 410, p. eaai7466, Oct. 2017.

[54] J. P. Bertram, C. A. Williams, R. Robinson, S. S. Segal, N. T. Flynn, and E. B. Lavik, "Intravenous Hemostat: Nanotechnology to Halt Bleeding," Sci. Transl. Med., vol. 1, no. 11, pp. 11ra22-11ra22, Dec. 2009.

[55] M. Yoshida et al., "Initial clinical trial of a novel hemostat, TDM-621, in the endoscopic treatments of the gastric tumors," J. Gastroenterol. Hepatol., vol. 29, no. S4, pp. 77-79.

[56] "A novel haemostatic agent based on self-assembling peptides in the setting of nasal endoscopic surgery, a case series." [Online]. Available: https://reader.elsevier.com/reader/sd/pii/S2210261217306028?token=4C10EBCAA10F3417 E3665E6F8D17722A0E24C3523AA910AE3F7848C5288F593549C9488AC450FE7DB5F2 17CFCBECC399. [Accessed: 08-Oct-2018].

[57] H. Goker et al., "Haemostatic Actions of the Folkloric Medicinal Plant Extract Ankaferd

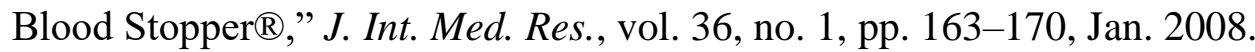

[58] O. Kandemir et al., "Demonstration of the histopathological and immunohistochemical effects of a novel hemostatic agent, ankaferd blood stopper, on vascular tissue in a rat aortic bleeding model," J. Cardiothorac. Surg., vol. 5, no. 1, Dec. 2010.

[59] K. E. You et al., "The effective control of a bleeding injury using a medical adhesive containing batroxobin," Biomed. Mater., vol. 9, no. 2, p. 025002, Jan. 2014.

[60] V. A. Kumar, N. C. Wickremasinghe, S. Shi, and J. D. Hartgerink, "Nanofibrous Snake Venom Hemostat," ACS Biomater. Sci. Eng., vol. 1, no. 12, pp. 1300-1305, Dec. 2015.

[61] L. R. Burnett et al., "Hemostatic properties and the role of cell receptor recognition in human hair keratin protein hydrogels," Biomaterials, vol. 34, no. 11, pp. 2632-2640, Apr. 2013.

[62] T. Aboushwareb et al., "A keratin biomaterial gel hemostat derived from human hair: Evaluation in a rabbit model of lethal liver injury," J. Biomed. Mater. Res. B Appl.

Biomater., vol. 90B, no. 1, pp. 45-54, Nov. 2008.

[63] T. A. Ostomel, Q. Shi, C.-K. Tsung, H. Liang, and G. D. Stucky, "Spherical Bioactive Glass with Enhanced Rates of Hydroxyapatite Deposition and Hemostatic Activity," Small, vol. 2, no. 11, pp. 1261-1265, Nov. 2006.

[64] G. Hu et al., "Antibacterial hemostatic dressings with nanoporous bioglass containing silver," Int. J. Nanomedicine, vol. 7, pp. 2613-2620, 2012.

[65] X. Wu et al., "Chemical characteristics and hemostatic performances of ordered mesoporous calcium-doped silica xerogels," Biomed. Mater., vol. 5, no. 3, p. 035006, Jun. 2010.

[66] C. Feng et al., "Chitosan-Coated Diatom Silica as Hemostatic Agent for Hemorrhage Control," ACS Appl. Mater. Interfaces, vol. 8, no. 50, pp. 34234-34243, Dec. 2016.

[67] S. R. MacNeill, C. M. Cobb, J. W. Rapley, A. G. Glaros, and P. Spencer, "In vivo comparison of synthetic osseous graft materials. A preliminary study," J. Clin. Periodontol., vol. 26, no. 4, pp. 239-245, Apr. 1999.

[68] C. Chen et al., "Biodegradable composite scaffolds of bioactive glass/chitosan/carboxymethyl cellulose for hemostatic and bone regeneration," Biotechnol. Lett., vol. 37, no. 2, pp. 457-465, Feb. 2015. 
[69] T. A. Ostomel, Q. Shi, and G. D. Stucky, "Oxide Hemostatic Activity," J. Am. Chem. Soc., vol. 128, no. 26, pp. 8384-8385, Jul. 2006.

[70] C. Dai et al., "Degradable, antibacterial silver exchanged mesoporous silica spheres for hemorrhage control," Biomaterials, vol. 30, no. 29, pp. 5364-5375, Oct. 2009.

[71] S. Pourshahrestani et al., "Potency and Cytotoxicity of a Novel Gallium-Containing Mesoporous Bioactive Glass/Chitosan Composite Scaffold as Hemostatic Agents," ACS Appl. Mater. Interfaces, vol. 9, no. 37, pp. 31381-31392, Sep. 2017.

[72] A. M. Alhalawani and M. R. Towler, "A novel tantalum-containing bioglass. Part I. Structure and solubility,” Mater. Sci. Eng. C, vol. 72, pp. 202-211, Mar. 2017.

[73] A. M. Alhalawani, C. Mehrvar, W. Stone, S. D. Waldman, and M. R. Towler, "A novel tantalum-containing bioglass. Part II. Development of a bioadhesive for sternal fixation and repair," Mater. Sci. Eng. C, vol. 71, pp. 401-411, 2017.

[74] H. R. W and O. C. T, "Tantalum oxide composition," US2491416 A, 13-Dec-1949.

[75] L. Vroman, A. L. Adams, G. C. Fischer, and P. C. Munoz, "Interaction of high molecular weight kininogen, factor XII, and fibrinogen in plasma at interfaces," Blood, vol. 55, no. 1, pp. 156-159, 1980.

[76] P. B. Samuels, H. Roedling, R. Katz, and J. J. Cincotti, "A new hemostatic clip: 2-year review of 1007 cases,” Ann. Surg., vol. 163, no. 3, pp. 427-431, Mar. 1966.

[77] D. Zhao, Y. Wan, and W. Zhou, Ordered mesoporous materials. Weinheim, Germany: Wiley-VCH, 2013.

[78] B. R. Barrioni, A. C. Oliveira, M. de F. Leite, and M. de M. Pereira, "Sol-gel-derived manganese-releasing bioactive glass as a therapeutic approach for bone tissue engineering," J. Mater. Sci., vol. 52, no. 15, pp. 8904-8927, Aug. 2017.

[79] A. Philippart et al., "Development of Novel Mesoporous Silica-Based Bioactive Glass Scaffolds with Drug Delivery Capabilities," Adv. Sci. Technol., vol. 96, pp. 54-60, Oct. 2014.

[80] J. Serra et al., "FTIR and XPS studies of bioactive silica based glasses," J. Non-Cryst. Solids, vol. 332, no. 1, pp. 20-27, 2003.

[81] A. T. Shah et al., "A study of the effect of precursors on physical and biological properties of mesoporous bioactive glass," J. Mater. Sci., vol. 50, no. 4, pp. 1794-1804, Feb. 2015.

[82] A. M. F. Alhalawani and M. R. Towler, "The effect of $\mathrm{ZnO} \leftrightarrow$ Ta 2 O 5 substitution on the structural and thermal properties of $\mathrm{SiO} 2$-ZnO-SrO-CaO-P 2 O 5 glasses," Mater. Charact., vol. 114, pp. 218-224, Apr. 2016.

[83] G. D. Boon, “An Overview of Hemostasis,” Toxicol. Pathol., vol. 21, no. 2, pp. 170-179, Mar. 1993.

[84] P. Hidnert, "Thermal expansion of tantalum," Bur. Stand. J. Res., vol. 2, no. 5, p. 887, May 1929.

[85] D. Bellucci, V. Cannillo, and A. Sola, "Coefficient of thermal expansion of bioactive glasses: Available literature data and analytical equation estimates," Ceram. Int., vol. 37, no. 8, pp. 2963-2972, Dec. 2011.

[86] J. Pérez-Pariente, F. Balas, and M. Vallet-Regí, "Surface and Chemical Study of $\mathrm{SiO}_{2} \cdot \mathrm{P}$ ${ }_{2} \mathrm{O} 5 \cdot \mathrm{CaO} \cdot(\mathrm{MgO})$ Bioactive Glasses," Chem. Mater., vol. 12, no. 3, pp. 750-755, Mar. 2000.

[87] F.-J. L. Murat, M. H. Ereth, Y. Dong, M. P. Piedra, and M. T. Gettman, "Evaluation of microporous polysaccharide hemospheres as a novel hemostatic agent in open partial 
nephrectomy: favorable experimental results in the porcine model," J. Urol., vol. 172, no. 3, pp. 1119-1122, Sep. 2004.

[88] M. Hoffman, "Remodeling the Blood Coagulation Cascade," J. Thromb. Thrombolysis, vol. 16, no. 1/2, pp. 17-20, Aug. 2003.

[89] D. Green, "Coagulation cascade," Hemodial. Int., vol. 10, no. S2, pp. S2-S4, Oct. 2006.

[90] G. Banfi, G. L. Salvagno, and G. Lippi, "The role of ethylenediamine tetraacetic acid (EDTA) as in vitro anticoagulant for diagnostic purposes," Clin. Chem. Lab. Med., vol. 45, no. 5, Jan. 2007.

[91] E. Bose and M. Hravnak, "Thromboelastography: A Practice Summary for Nurse Practitioners Treating Hemorrhage," J. Nurse Pract., vol. 11, no. 7, pp. 702-709, Jul. 2015.

[92] L. T. da Luz, B. Nascimento, and S. Rizoli, "Thrombelastography (TEG®): practical considerations on its clinical use in trauma resuscitation," Scand. J. Trauma Resusc. Emerg. Med., vol. 21, no. 1, p. 29, 2013. 